\title{
Cause Analysis on Eastward Movement of Southwest China Vortex and Its Induced Heavy Rainfall in South China
}

\author{
Yongren Chen, ${ }^{1,2}$ Yueqing $\mathrm{Li}^{1}{ }^{1}$ and Tianliang $\mathrm{Zhao}^{3}$ \\ ${ }^{1}$ Institute of Plateau Meteorology, CMA, Chengdu, Sichuan 610072, China \\ ${ }^{2}$ Sichuan Provincial Meteorological Observatory, Chengdu, Sichuan 610072, China \\ ${ }^{3}$ Collaborative Innovation Center on Forecast and Evaluation of Meteorological Disasters, \\ Key Laboratory for Aerosol-Cloud-Precipitation of China Meteorological Administration, \\ Nanjing University of Information Science and Technology, Nanjing 210044, China \\ Correspondence should be addressed to Yueqing Li; yueqingli@163.com
}

Received 12 October 2014; Revised 30 December 2014; Accepted 18 January 2015

Academic Editor: Klaus Dethloff

Copyright (C) 2015 Yongren Chen et al. This is an open access article distributed under the Creative Commons Attribution License, which permits unrestricted use, distribution, and reproduction in any medium, provided the original work is properly cited.

\begin{abstract}
The movement of southwest China vortex (SWV) and its heavy rainfall process in South China had been investigated during June 11-14, 2008. The results show that under the steering of upper-level jet (ULJ) and mid-level westerly trough, SWV moved eastward from southern Sichuan Plateau, across eastern Yunnan-Guizhou Plateau to South China, forming an obvious heavy rain belt. SWV developed in the large storm-relative helicity (SRH) environment, as environmental wind field continuously transferred positive vorticity to it to support its development. The thermodynamic structures of distinctive warm (cold) advections in front (rear) of the SWV movement are also important factors for the SWV evolutions with a southwest low-level jet (LLJ) and vertical wind shear. SWV development was associated with the distributions of negative MPV1 (the barotropic item of moist potential vorticity) and positive MPV2 (the baroclinic item of it). The MPV1 and MPV2 played the dominant role in the formation and the evolution of SWV, respectively. The mesoscale convective systems (MCSs) frequently occurred and persisted in water vapor convergence areas causing the severe heavy rainfall. The areas of high moist helicity divergence and heavy rainfall are consistent, and the moist helicity divergence could be a good indicator for heavy rainfall occurrence.
\end{abstract}

\section{Introduction}

Generated by the complex terrain in the eastern edge of Tibetan Plateau (TP), Southwest China vortex (SWV), also known as a meso- $\alpha$ scale low vortex, typically originates in Southwest China $\left(98-108^{\circ} \mathrm{E}, 26-33^{\circ} \mathrm{N}\right)$ in the lower troposphere below $700 \mathrm{hPa}$. Because the very sparse meteorological observations on the TP with complex topography have limited our understanding of the SWV, this leads to the large uncertainties and difficulties in prediction of the SWV and disastrous weather downstream from the TP. SWV was generally a shallow weather system in early formation; yet when it moved eastward, it can produce severe weather impacts [1]. For instance, a flood-causing heavy rainfall of Sichuan basin in July $1981[1,2]$, a heavy rainfall and flood disaster in the Yangtze River valley in summer 1998 [3], and a continuous heavy rainfall in South China in mid-June
2008 [4] all closely relate to SWV. SWV played significant roles in many heavy rainfall events and was the major influencing system for the summer-half year heavy rainfall in China $[1,5]$. The study of SWV-induced rainfalls [6] has suggested that the intensity and frequency of heavy rainfalls caused by SWV can be second only to tropical typhoons and residual low pressure. As a result, the forming, developing, and consequential floods of SWV are hot study topics among meteorologists and weather-forecasters. Numerous studies have been made in statistical analysis on the source region and movement path of low vortexes $[7,8]$, discussion on structural features of low vortexes and causes of their formation and development [1,9-13], and case studies [1416] and numerical simulations [17] on heavy rainfalls caused by SWV. With more common applications of satellite and radar observation, further knowledge about formation and development of SWV, its internal physical characteristics, 
and the development of heavy rainfalls caused by it has been obtained gradually, and some initial achievements have been made in these areas $[18,19]$. In fact, life cycles and movement paths of different SWV vary greatly, and these differences have significant influences on the intensity and rain belts of the rainfalls. Therefore, it is important to thoroughly understand and accurately predict the life cycles and movement paths of SWV. Using daily meteorological observation data of 15 years, Chen et al. [8] divided the movement paths of SWV into four types, the northeast, the eastward, the southeast, and little movement; these four types each account for $33.3 \%, 50.0 \%, 5.0 \%$, and $11.7 \%$ of moving low vortexes. Apparently, SWV influences not only Southwest China in east TP, but also East China by moving eastward; and the influenced region of the SWV is closely related to its movement path. In particular, SWV may greatly influence the precipitation in South China, including the heavy rainfall in preflood season. However, few studies have been conducted on continuous heavy rainfall in South China caused by SWV. To analyze the eastward movement of SWV and the heavy rainfall-inducing physical process and reveal the physical causes of SWV's formation and development as well as their mesoscale structure, the analysis is deeply performed in this study with a continuous severe heavy rainfall in South China during 11-14 June 2008.

This paper is organized as follows. The second section presents the data and analyzing methods employed in this study. The third section describes the relationship between the pathway of SWV and heavy rainfall. The fourth section analyzes the reason for and environmental factors of the large-scale circulation during SWV movement. In the fifth section, physical process of the SWV inducing heavy rainfall is analyzed. Section 6 concludes this paper.

\section{Data and Methods}

2.1. Data. Data sources include the following: the FNL (Final) Operational Global Analysis data of National Centers for Environmental Prediction (NCEP) with $1^{\circ} \times 1^{\circ}$ grids and $6 \mathrm{~h}$ temporal resolution (http://rda.ucar.edu/); the TBB data from the FY2D static weather satellite provided by the meteorological satellite center of China Meteorological Administration (CMA), with $0.1^{\circ} \times 0.1^{\circ}$ grids (http://www.nsmc.cma.gov.cn/NSMC/Home/Index.html); and observational precipitation data provided by CMA.

2.2. Methods. To analyze the influence of environmental wind field on the low vortex, storm-relative helicity (SRH) [20-23] is adopted, and the mathematical expression is

$$
\mathrm{SRH}=\int_{0}^{h}(\vec{V}-\vec{C}) \cdot \vec{\omega}_{h} d z
$$

where $\vec{V}$ is the horizontal environmental wind vector, $\vec{C}$ is the storm motion vector, $\vec{\omega}_{h}$ is the horizontal vortex vector, and $\vec{\omega}_{h}=(\nabla \times \vec{V})_{h}=(\partial w / \partial y-\partial v / \partial z, \partial u / \partial z-\partial w / \partial x)$. Evidently, $\mathrm{SRH}$ reflects the rotation degree of the environmental wind field in atmosphere layer of certain thicknesses and vorticity input into the convective system. In practice, the calculation formula was proposed by Davies-Jones et al. [24]. Consider

$$
\mathrm{SRH}=\sum_{n=0}^{n-1}\left[\left(u_{n+1}-c_{x}\right)\left(v_{n}-c_{y}\right)-\left(u_{n}-c_{x}\right)\left(v_{n+1}-c_{y}\right)\right] \text {, }
$$

where $c_{x}$ and $c_{y}$ are horizontal components of the storm motion $\vec{C}$. In this paper, the $75 \%$ of the speed of massweighted mean wind from $950 \mathrm{hPa}$ to $400 \mathrm{hPa}$ and its direction deflected towards the right $40^{\circ}$ are considered the storm velocity [25].

Only considering vertical helicity and water vapor flux divergence factor, moist helicity divergence (MHD) is defined $[26,27]$; that is,

$$
\mathrm{MHD}=\omega \xi \nabla \cdot \vec{V} q
$$

where $\omega$ is the vertical velocity of P-coordinate, $\xi$ is the vertical vorticity, and $\nabla \cdot \vec{V} q$ is water vapor flux divergence.

\section{The Pathway of SWV Movement and Heavy Rainfall}

Figure 1 shows the pathway of SWV movement (Figure 1(a)) and the center vorticity of SWV (Figure 1(b)) in each $6 \mathrm{~h}$, the low vortex generated in south Sichuan Plateau region $\left(29^{\circ} \mathrm{N}\right.$, $102.5^{\circ} \mathrm{E}$ ) at 1800 UTC June 10,2008 , and moved southward along the Yunnan-Guizhou border until 1800 UTC June 11. Moving pathway was meridional distribution from north to south (this is the first stage). The second stage started from 1800 UTC June 11, 2008, when low vortex entered Guangxi province and developed intensively and then entered Jiangxi province via Hunan and north Guangdong, till its disappearance; this stage lasted more than 3 days which is a long life cycle. Also, the intensity of SWV was generally lower than 10 $\times 10^{-5} \mathrm{~s}^{-1}$ in the first stage and greater than $10 \times 10^{-5} \mathrm{~s}^{-1}$ in the second stage (Figure 1(b)), implying that the low vortex became deeper in South China area.

Accompanying the SWV movement (Figure 1), the rain belt was built first from north to south and then gradually from west to east according to distribution of $24 \mathrm{~h}$ accumulative precipitation (Figure 2). The heavy rainfall started in south Sichuan Plateau (zone A in Figure 2(a)). Heavy rainfall also occurred in south Yangtze River valley (zone B in Figure 2(a)), but it was related to the shear line. As of 0000 UTC on June 12 (Figure 2(b)), heavy rainfall with values of 50-200 mm mainly concentrated in Yunnan-Guizhou border and north Guangxi (zone C in Figure 2(b)). As of 0000 UTC on June 13 (Figure 2(c)), heavy rainfall (values of 100$300 \mathrm{~mm}$ ) was mainly in Guangxi and Guangdong (zone D in Figure 2(c)). At 0000 UTC June 14 (Figure 2(d)), heavy rainfall was mainly in Guangdong, south Hunan, and Jiangxi (zone E in Figure 2(d)).

Apparently, the rain belt patterns were consistent with the low vortex's movement path. In order to understand the physical process of the heavy rainfall, the circulation background, where SWV moved and developed, and structural 


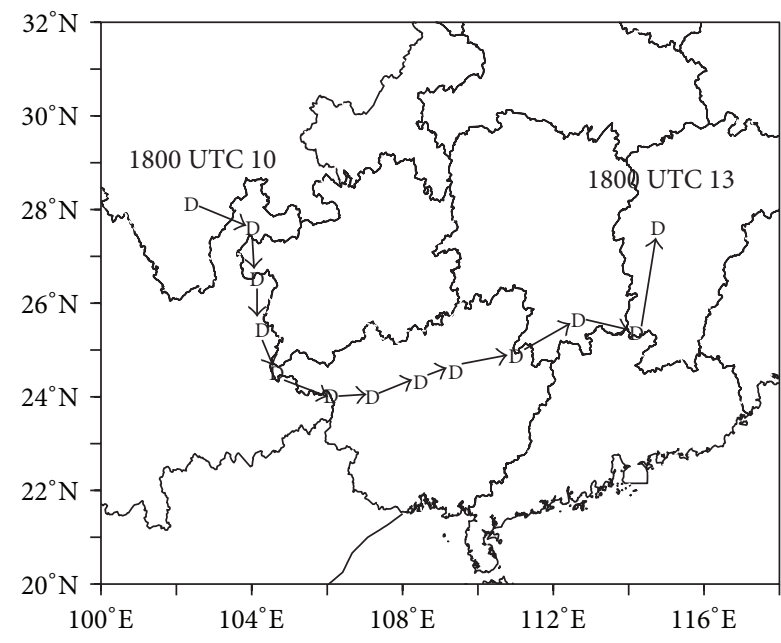

(a) $\left(10^{-5} \mathrm{~s}^{-1}\right)$

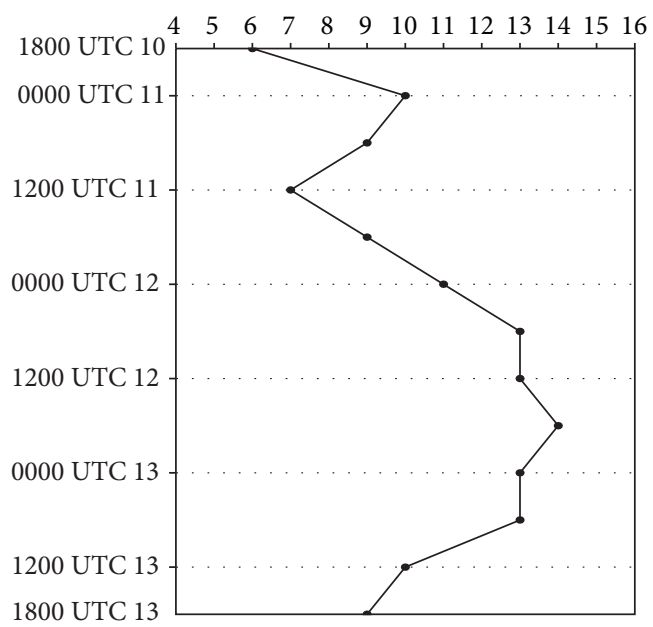

(b)

Figure 1: The SWV (a) movement pathway (dark line with arrows) and (b) center vorticity variation at 700 hPa tracked every 6 hours from 18 UTC June 10, 2008 to 18 UTC June 13, 2008 (the unit of vorticity is $10^{-5} \mathrm{~s}^{-1}$ ); D indicating the SWV centers.

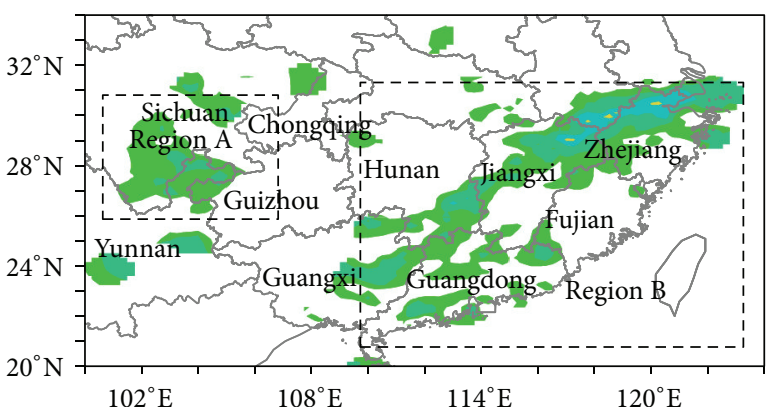

(a)

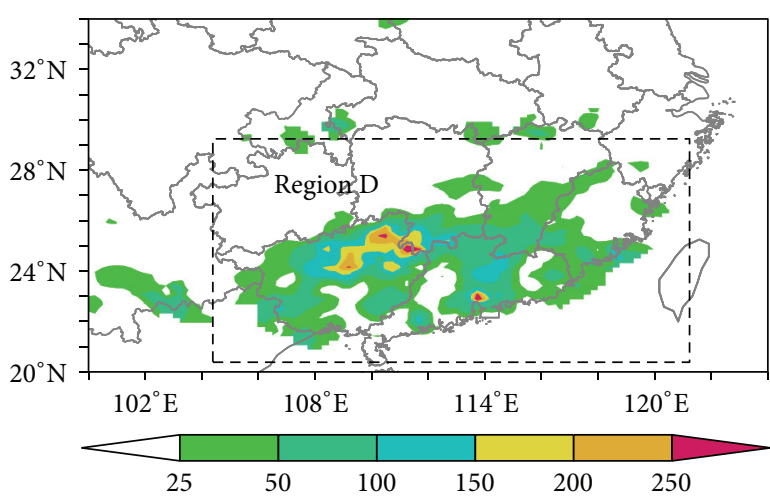

(c)

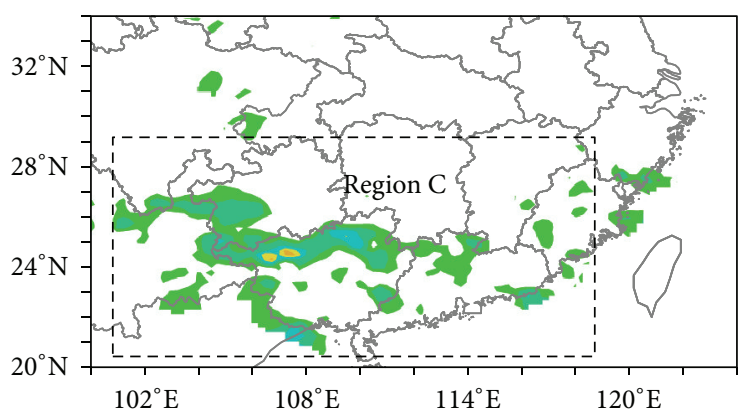

(b)

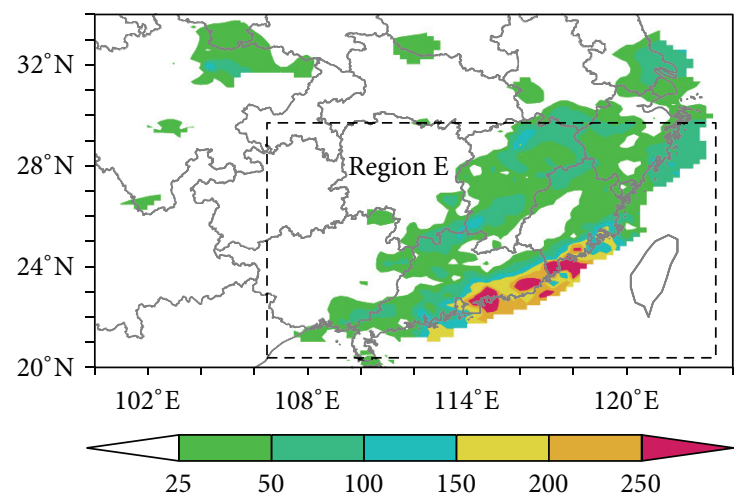

(d)

FIGURE 2: The daily precipitation distribution (mm) from 00 UTC to 24 UTC of (a) June 11, (b) June 12, (c) June 13, and (d) June 142008.

characteristics and causes of intense development of SWV were further analyzed in the next section.

\section{Causes on Development of the SWV}

4.1. Large-Scale Circulation. Favorable large-scale circulation is crucial for movement and development of SWV [1]. The time-mean circulation showed that the SWV movement was closely related to the $250 \mathrm{hPa} U \mathrm{LJ}(\geqq 30 \mathrm{~m} / \mathrm{s})$, strong ascending motion in front of westerly trough of $500 \mathrm{hPa}$ and LLJ of $700 \mathrm{hPa}$ in the first stage (Figures 3(a), 3(c), and 3(e)) and the second stage (Figures 3(b), 3(d), and 3(f)). This relation is reflected in three aspects. (1) The SWV always moved along the strong divergence area on the right side of $250 \mathrm{hPa}$ ULJ 


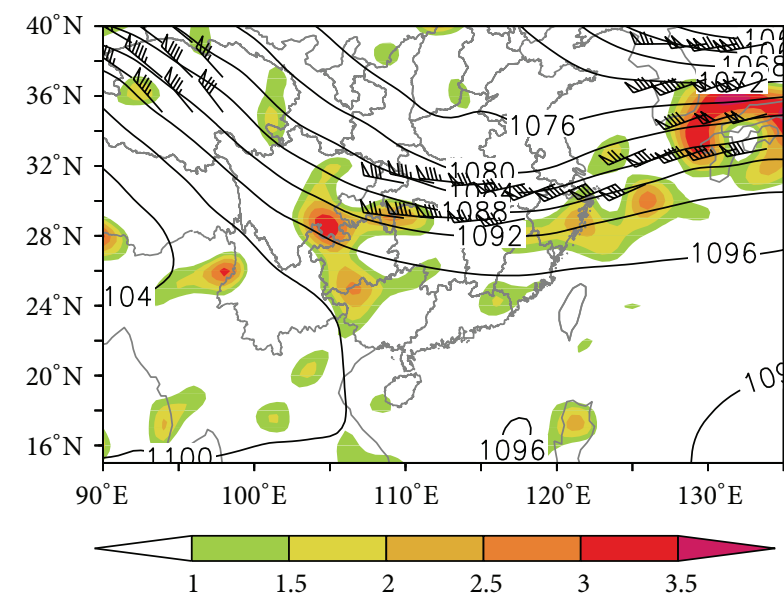

(a)

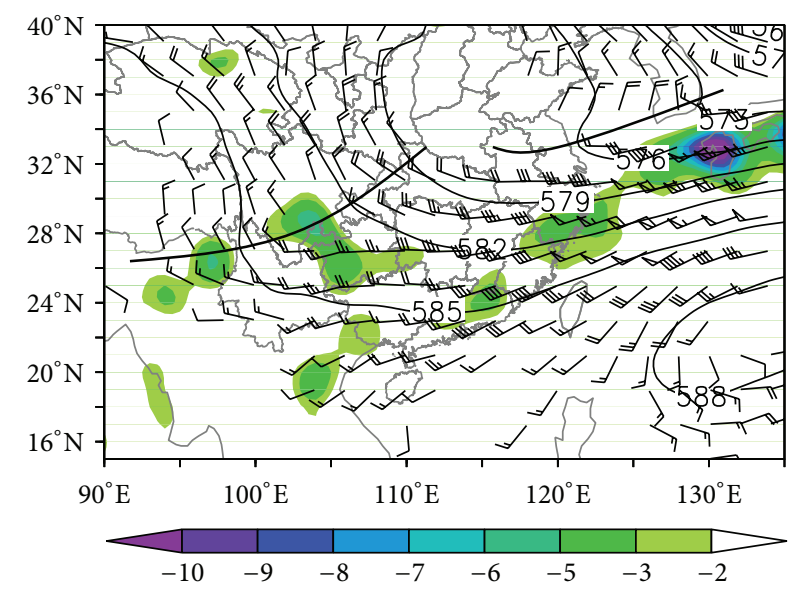

(c)

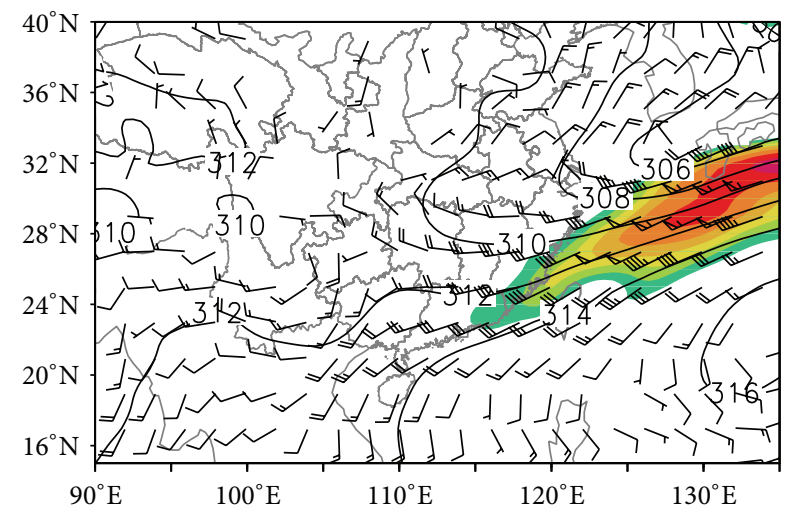

(e)

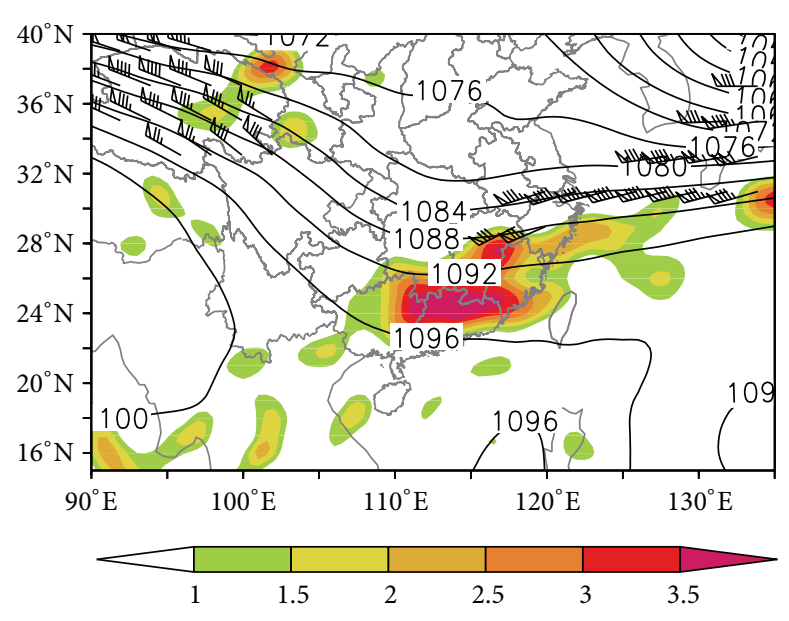

(b)

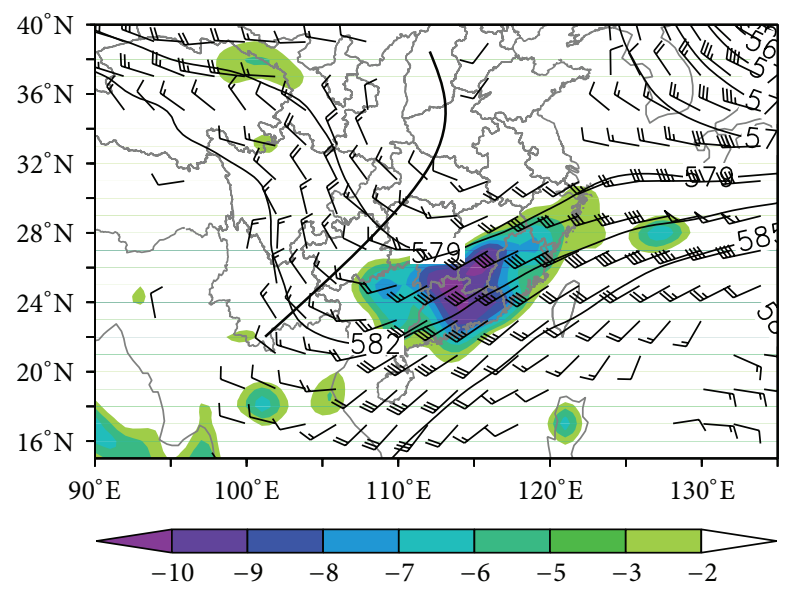

(d)

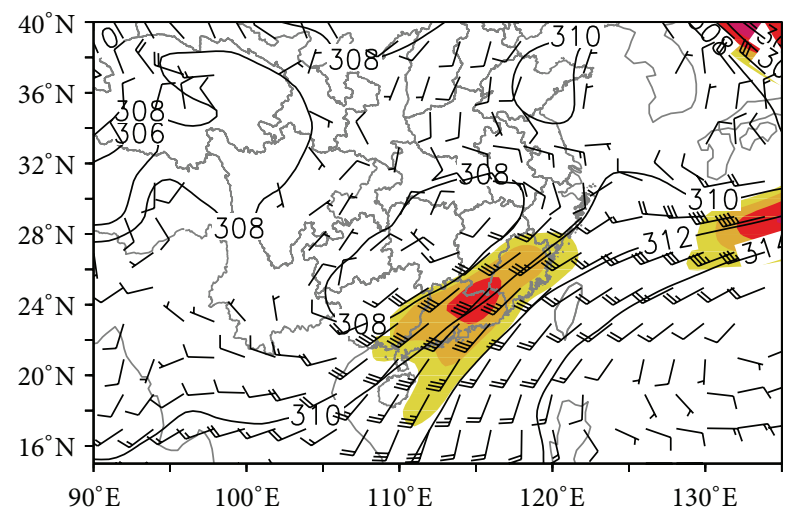

(f)

Figure 3: Wind and geopotential height fields at (a, b) $250 \mathrm{hPa},(\mathrm{c}, \mathrm{d}) 500 \mathrm{hPa}$, and (e, f) $700 \mathrm{hPa}$. (a), (c), and (e) are averaged from $18 \mathrm{UTC}$ of June 10 to 18 UTC of June 11, 2008. (b), (d), and (f) are averaged from 18 UTC of June 11 to 18 UTC of June 13, 2008. The shaded areas indicate the divergence $\left(10^{-5} \mathrm{~s}^{-1}\right)$ in (a) and (b), the vertical velocity $(\mathrm{Pa} / \mathrm{s})$ in $(\mathrm{c})$ and $(\mathrm{d})$, and the horizontal wind speed $(\geq 12 \mathrm{~m} / \mathrm{s})$ in $(\mathrm{e})$ and $(\mathrm{f})$.

entrance. There was a strong divergence area in south Sichuan and Yunnan-Guizhou border in the first stage (Figure 3(a)), where the corresponding SWV movement concentrated. In the second stage (Figure 3(b)), the strong divergence area was in South China, where the corresponding low vortex movement concentrated. (2) The $500 \mathrm{hPa}$ geopotential height was lower in the west and higher in the east, which were configuration results of westerly trough and West-Pacific subtropical anticyclone (WPSH), and low vortex always was in strong ascending motion area in front of westerly trough. 


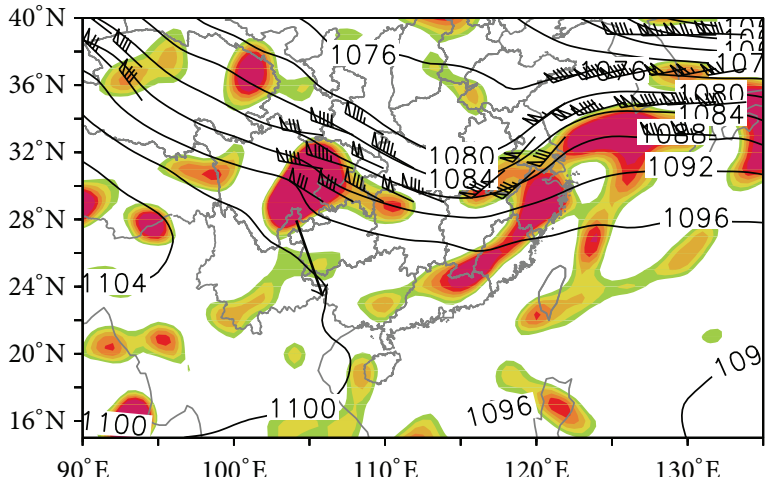

(a) $250 \mathrm{hPa}$ at $0000 \mathrm{UTC} 11$

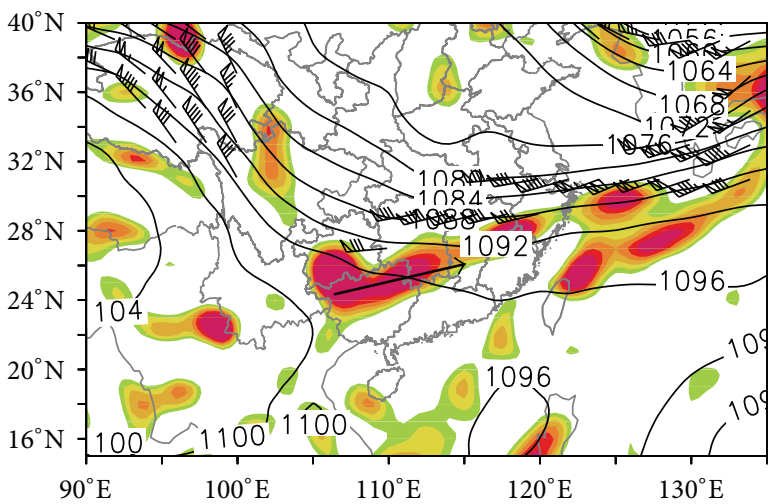

(c) $250 \mathrm{hPa}$ at $1800 \mathrm{UTC} 11$

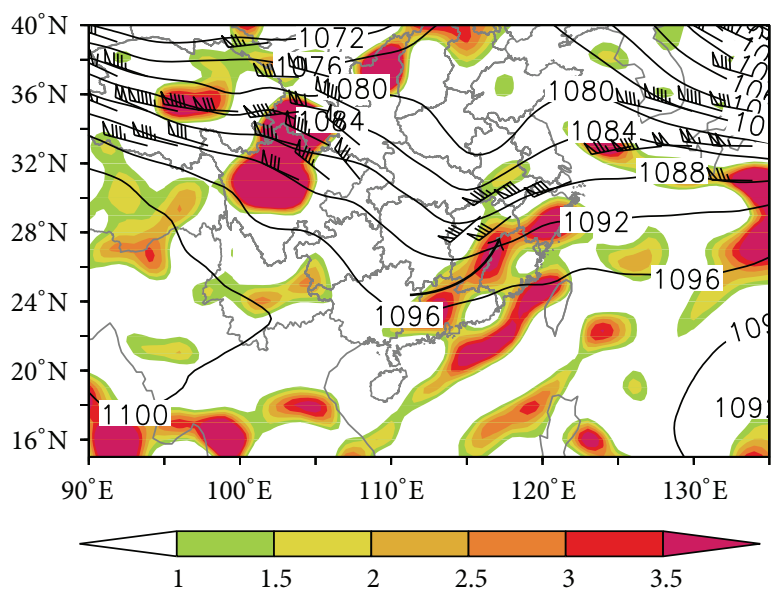

(e) $250 \mathrm{hPa}$ at $1200 \mathrm{UTC} 13$

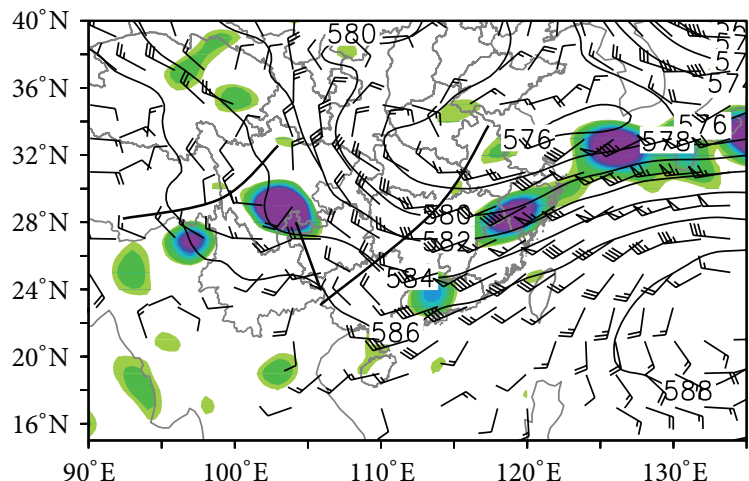

(b) $500 \mathrm{hPa}$ at $0000 \mathrm{UTC} 11$

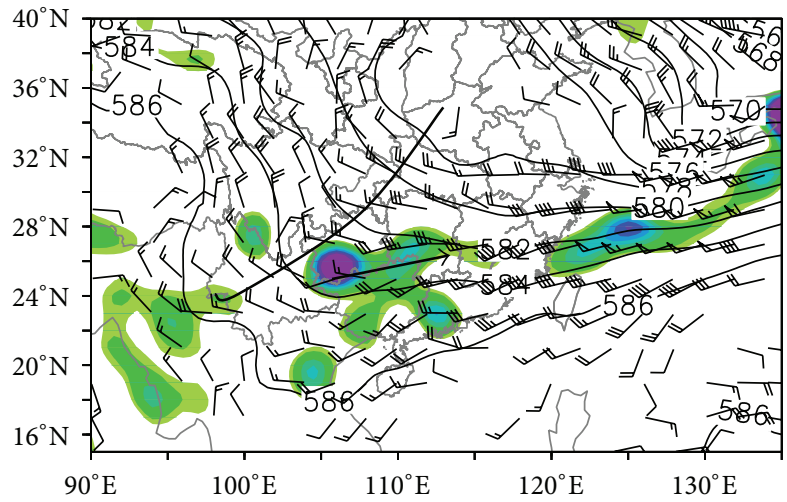

(d) $500 \mathrm{hPa}$ at $1800 \mathrm{UTC} 11$

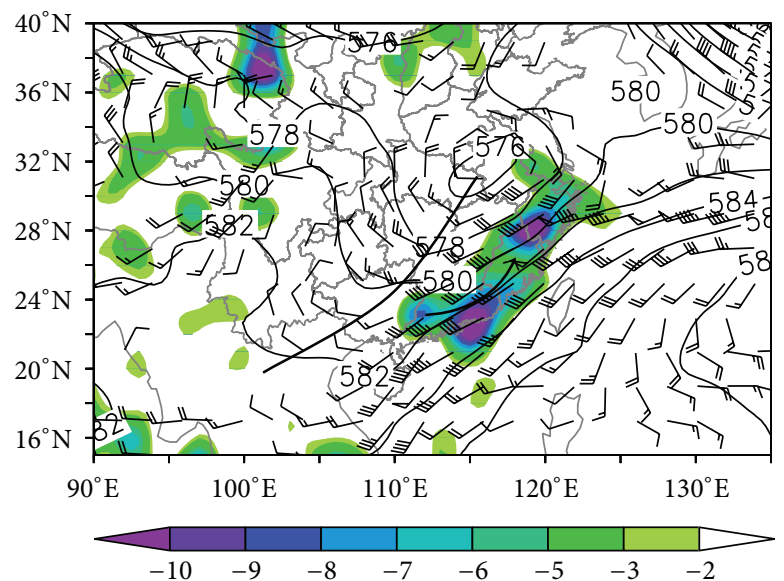

(f) $500 \mathrm{hPa}$ at $1200 \mathrm{UTC} 13$

Figure 4: As in Figure 3, but at $250 \mathrm{hPa}$ and $500 \mathrm{hPa}$ with the dark lines standing for troughs and the arrow for the SWV motion direction.

For example, the strong ascending motion was in YunnanGuizhou border area (Figure 3(c)) in the first stage and South China area (Figure $3(\mathrm{~d})$ ) in the second phase. (3) In the first stage (Figure 3(e)), convergence stream field of the low vortex was in Yunnan-Guizhou border area, but the LLJ was on ocean surface in the east; in the second stage (Figure 3(f)), the convergence stream field was mainly in Guangxi and Guangdong with obvious LLJ in front of the vortex.

Discussed above is the time-mean circulation, the distribution of atmosphere circulation is drawn at different times
(Figure 4), and $250 \mathrm{hPa}$ ULJ was in north Sichuan and on the right side of its entrance was divergence area at 0000 UTC 11 (Figure 4(a)). The $500 \mathrm{hPa}$ westerly troughs were fluctuant and exhibited characteristics of ladder troughs, one of troughs located over the western Sichuan and ascending motion in front of it corresponded to the movement area of low vortex (Figure 4(b)), also there was another one in east-central China, and such ladder trough distribution was conducive to the SWV move southward. At 1800 UTC 11, the ULJ had pushed to Chongqing area, strong divergence area was above 
South China (Figure 4(c)), the $500 \mathrm{hPa}$ step troughs had merged and formed a westerly trough with greater meridional span, and vertical ascending motion in front of the trough was in Guangxi area, while corresponding low vortex had changed movement direction and entered Guangxi. By 1200 UTC 13, the ULJ moved to the downstream of the Yangtze River valley, and the westerly trough moved eastward slightly. Corresponding low vortex continued moving eastward in the area of high-level strong divergence and ascending motion in front of $500 \mathrm{hPa}$ westerly trough.

Under the large-scale atmospheric circulation, SWV had closely relationships with ULJ and strong ascending motion in front of the westerly trough. When ULJ develops southwards, and $500 \mathrm{hPa}$ westerly trough is fluctuant and exhibits ladder troughs, it is conducive to the southward movement of low vortex; when ULJ and $500 \mathrm{hPa}$ westerly trough move eastward, it is conducive to the eastward movement of low vortex.

\subsection{Environmental Field Conditions}

4.2.1. Vertical Wind Shear and Storm-Relative Helicity. The meridional profile (Figures 5(a) and 5(b)) and zonal profile (Figures 5(c)-5(f)) were taken along the vortex center. In the vertical direction, wind and vorticity variations exhibited some features. (1) Vertical wind shear existed; the areas with significant vertical wind shear typically imply strong ascending motions, which are conducive to formation and development of SWV. (2) Positive vorticity was deep $(950 \mathrm{hPa}-400 \mathrm{hPa})$; it could form positive vorticity cylinder, which provided dynamic conditions for development of the low vortex. (3) LLJ existed; during the intense development of low vortex, LLJ could reach $20 \mathrm{~m} / \mathrm{s}$ (Figures 5(a) and $5(e))$. In addition, low vortex usually moved along southerly wind. When it moved from north to south, the low-level wind was south wind; when it moved from west to east, there was southwest wind in front of it; in such environmental condition, how to obtain positive vorticity from environmental field for the SWV development? Distribution of SRH was analyzed (Figure 6), SRH shows that relative velocity of convective system ( $\mathrm{V}-\mathrm{C}$ ) transports environmental vorticity to convective systems, the updraft changes vorticity of entering the convective systems into vertical vorticity, and vertical vorticity is crucial to the formation of convective systems. Therefore, the environment condition with high SRH is conducive to formation and development of convective systems and low vortexes [21, 25]. There was high SRH in Yunnan-Guizhou area at 0000 UTC 11 (Figure 6(a)) and 1200 UTC 11 (Figure 6(b)), where the SWV movement concentrated; $700 \mathrm{hPa}$ wind field showed meso- $\alpha$ scale and meso- $\beta$ scale features. Also there was high SRH value in front of the low vortex's moving direction. When the SWV was active in South China (Figures 6(c)-6(f)), the distribution of SRH indicated that the environmental vorticity was continuously transferred to SWV when wind field has obvious rotations and significant ascending speed. Therefore, vertical wind shear, deep positive vorticity, and strong ascending motion are conducive to forming of high SRH, formation and development of low vortexes.
4.2.2. Thermal Conditions. For the physical factors that influence SWV, besides dynamic conditions, thermodynamic factors are also important. Distribution of pseudo equivalent potential temperature $\left(\theta_{\text {se }}\right)$ and its advections were drawn at different time points (Figure 7 ). The $\theta_{\text {se-lines were concen- }}$ trated and gradually decreased with height below $700 \mathrm{hPa}$, indicating that low level atmosphere was unstable, thermal instability is an important condition for development of SWV [1]. As seen from Figure 7, there was cold advection on north side of the low vortex and warm advection on south side at 0000 UTC 11 (Figure 7(a)); such thermal structure is conducive to SWV move southward. At 1200 UTC 11 (Figure $7(\mathrm{~b})$ ), the structure of $\theta_{\text {se }}$ advection became cold (warm) in front (rear) of SWV; SWV weakened at this time (Figure 1(b)). To large extent, in order to sustain or develop for SWV, the thermal structure such as warm (cold) advection in front (rear) of low vortex should be built; otherwise it is difficult to develop. And for such the coldwarm advection structure, in addition to promoting vortex moving development, does it also has an important impact on the vortex suddenly to change its movement direction? To analyze thermodynamic environment for such sudden direction change, meridional and zonal profile sections of $\theta_{\text {se }}$ were analyzed at 0000 UTC 12; on meridional profile section (Figure 7(c)), the low vortex was surrounded basically by warm advections, while on the zonal profile (Figure $7(d)$ ), there was warm (cold) advection in front (rear) of the low vortex; the warm-cold interaction structure was distinctive, and cold advection promoted SWV move eastward. Also, such structure of cold and warm advections was fully reflected in the zonal movement of low vortex (Figures 7(e) and 7(f)). Furthermore, the structure of cold and warm advection was obvious at $700 \mathrm{hPa}$ in Yunnan-Guizhou area (Figure $7(\mathrm{~h})$ ) and South China area (Figure 7(i)), and the zero line of advection was basically consistent with movement path of the low vortex. When low-level atmosphere was unstable, it was conductive to vortex form and development; the sustaining of $\theta_{\text {se }}$ warm (cold) advection in front (rear) of the vortex was conducive to move towards warm area.

Under the combined effect of dynamic and thermal conditions, the moist potential vorticity (MPV) $[28,29]$ is adopted for diagnostic analysis; MPV is calculated as

$$
\mathrm{MPV}=-g(\xi+f) \frac{\partial \theta_{\mathrm{se}}}{\partial p}+g\left(\frac{\partial v}{\partial p} \frac{\partial \theta_{\mathrm{se}}}{\partial x}-\frac{\partial u}{\partial p} \frac{\partial \theta_{\mathrm{se}}}{\partial y}\right) .
$$

When MPV is divided into moist barotropic item (MPV1) and moist baroclinic item (MPV2), one has the following:

$$
\begin{gathered}
\text { MPV } 1=-g(\xi+f) \frac{\partial \theta_{\mathrm{se}}}{\partial p}, \\
\mathrm{MPV} 2=g\left(\frac{\partial v}{\partial p} \frac{\partial \theta_{\mathrm{se}}}{\partial x}-\frac{\partial u}{\partial p} \frac{\partial \theta_{\mathrm{se}}}{\partial y}\right) .
\end{gathered}
$$

Generally, absolute vorticity $(\xi+f)$ is a positive value, when $\partial \theta_{\text {se }} / \partial p>0$ (i.e., the convective unstable), MPV1 $<0$. Only when MPV2 > 0 , vertical vorticity could increase greatly. MPV is in the unit of PVU $\left(1 \mathrm{PVU}=10^{-6} \mathrm{~m}^{2} \cdot \mathrm{K} \cdot \mathrm{s}^{-1}\right.$. $\mathrm{kg}^{-1}$ ), and $\theta_{\text {se }}$ is in the unit of $\mathrm{K}$. Based on the analysis on 


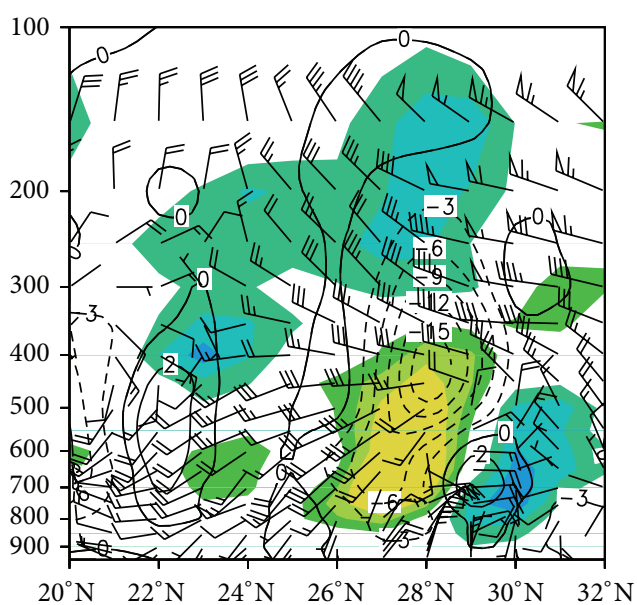

(a) 0000 UTC 11

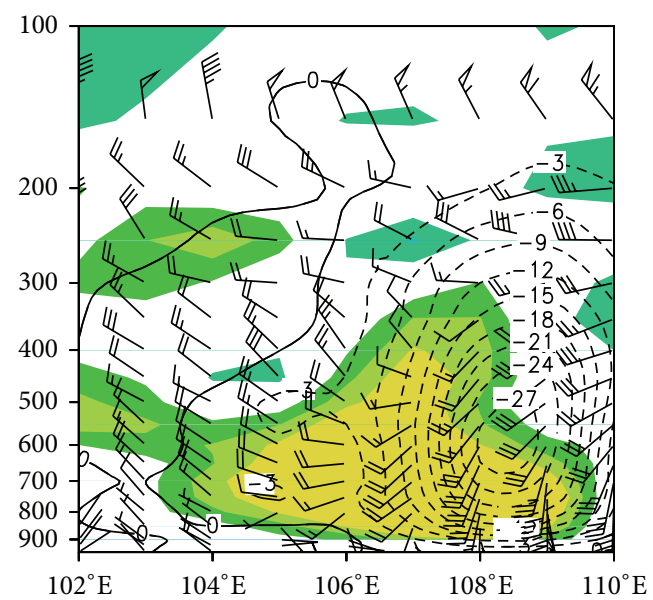

(c) 0000 UTC 12

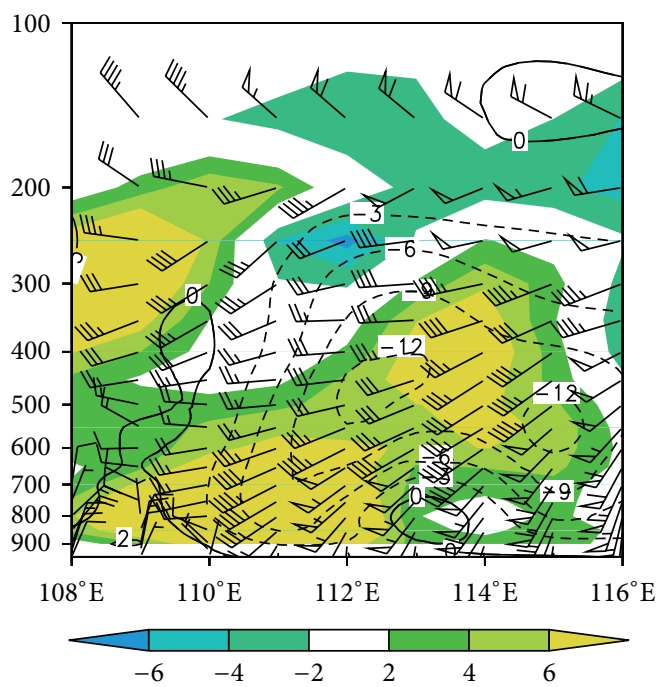

(e) 0000 UTC 13

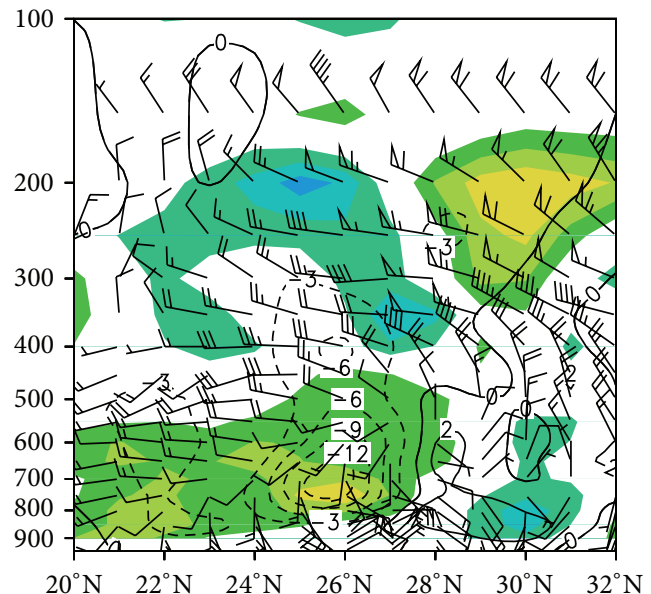

(b) 1200 UTC 11

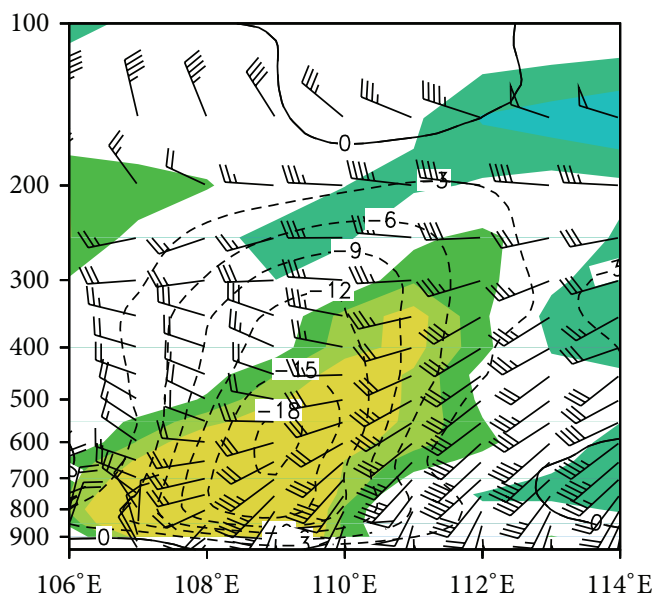

(d) 1200 UTC 12

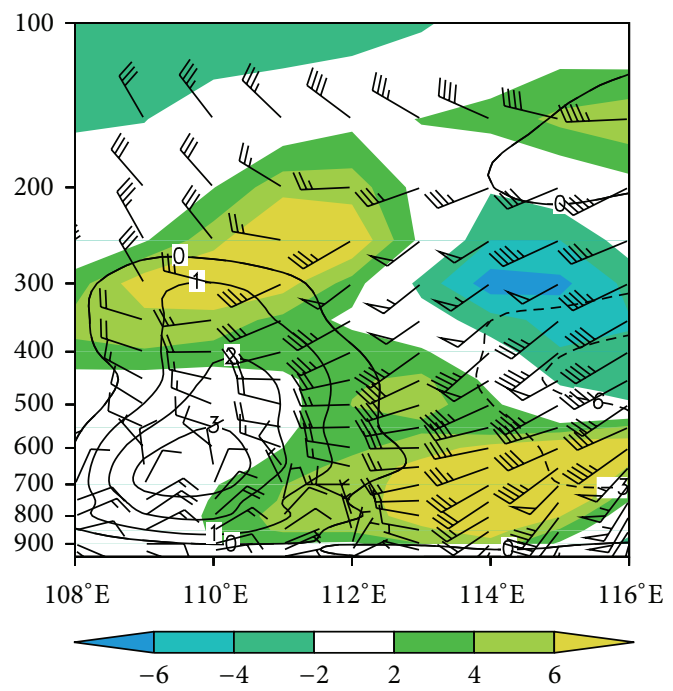

(f) 1200 UTC 13

FIGURE 5: Vertical distribution of wind and vertical vorticity distribution $\left(\times 10^{-5} \mathrm{~s}^{-1}\right)$ (colored areas indicate vorticity; solid lines indicate vertical velocities in the unit of $\times 10^{-1} \mathrm{~Pa} / \mathrm{s}$; horizontal wind speed is in the unit of $\mathrm{m} / \mathrm{s}$ ) at the sections along (a) $104^{\circ} \mathrm{E}$; (b) $105^{\circ} \mathrm{E}$; (d) $24^{\circ} \mathrm{N}$; and (c, e, and f) $25^{\circ} \mathrm{N}$. 


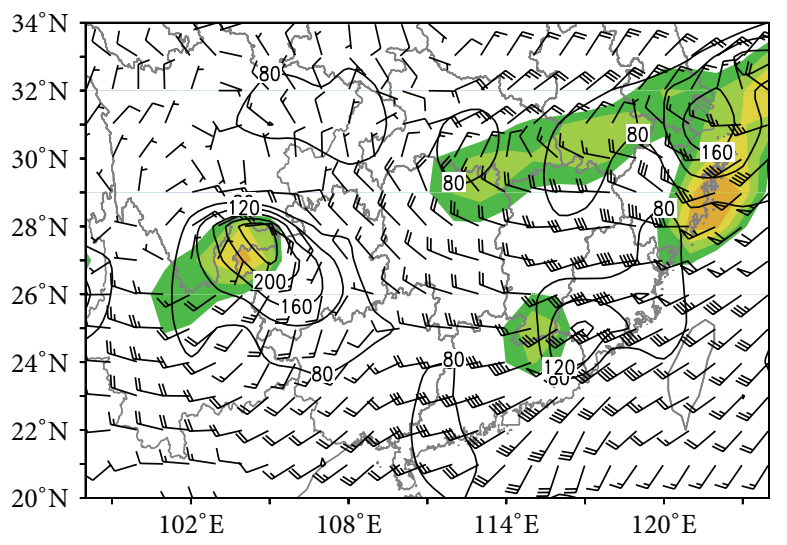

(a) 0000 UTC 11

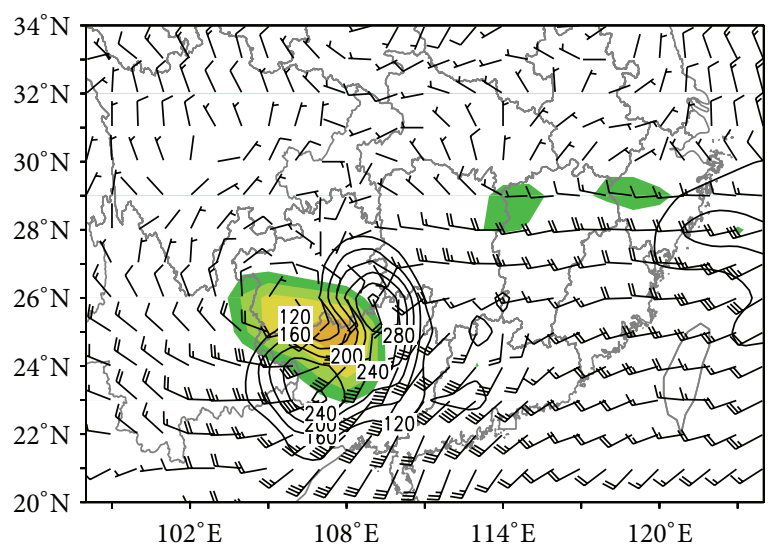

(c) 0000 UTC 12

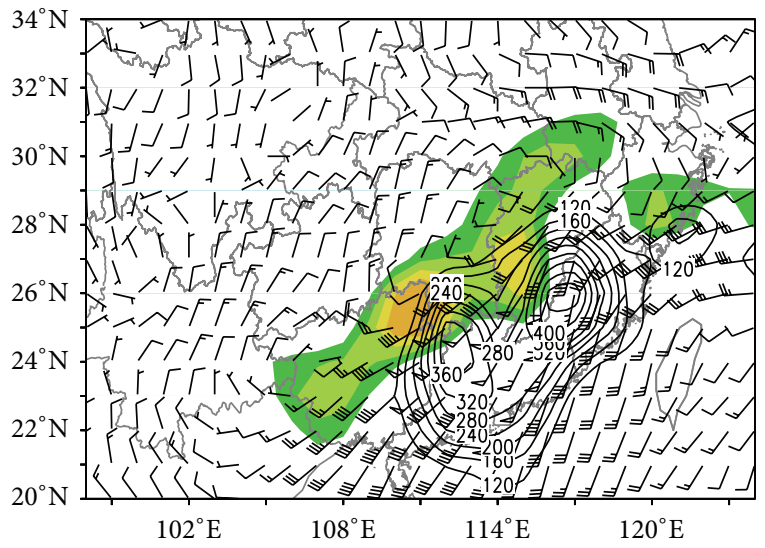

(e) 0000 UTC 13

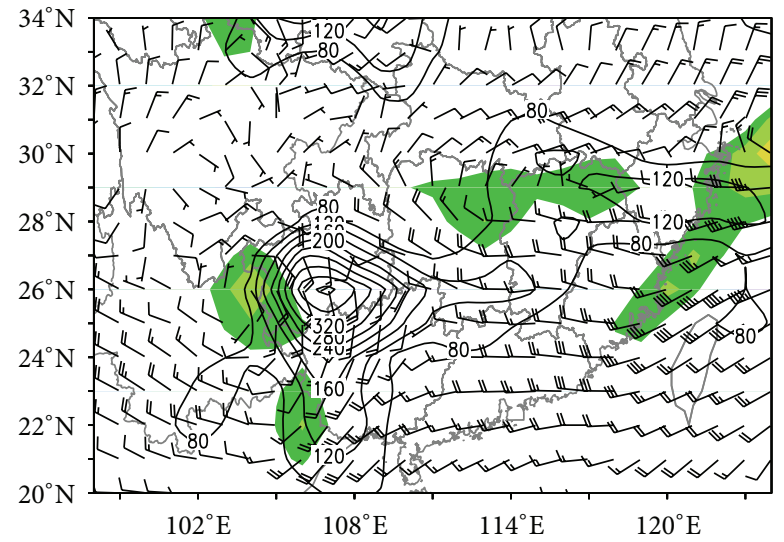

(b) 1200 UTC 11

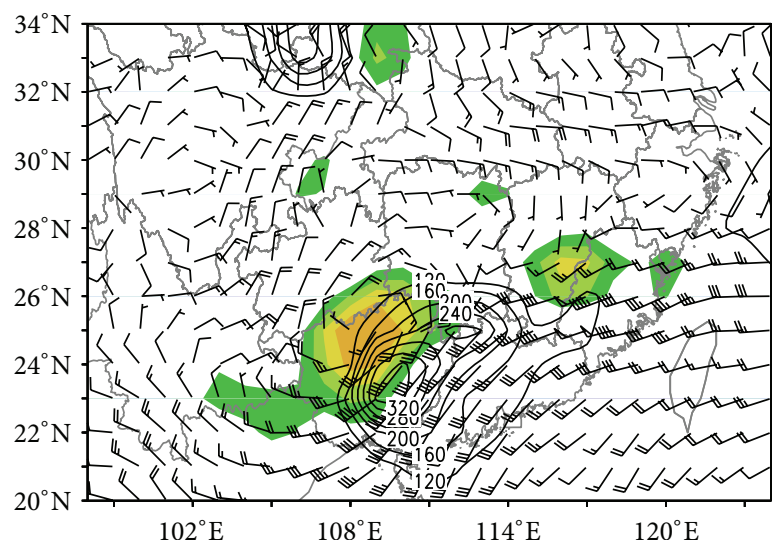

(d) 1200 UTC 12

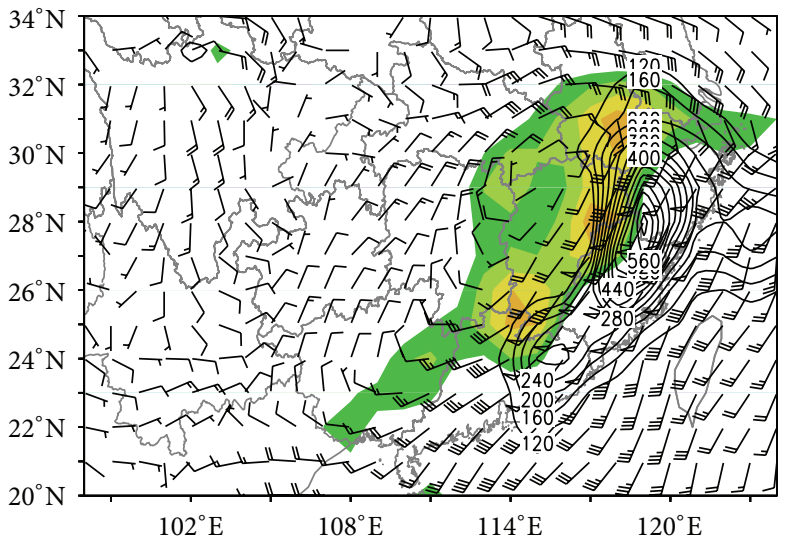

(f) 1200 UTC 13

FIgURE 6: The distribution of storm relative helicity (solid lines in $\mathrm{m}^{2} / \mathrm{s}^{2}$ ) and $700 \mathrm{hPa}$ horizontal wind vector (m/s) and vorticity (shaded in $10^{-5} \mathrm{~s}^{-1}$ ) over June 11-13, 2008.

the SWV-occurrence of June 10-14, 2008, it is revealed that both moist barotropic (MPV1) and moist baroclinic (MPV2) of low-level atmosphere play an important role in the SWV movement and development. The atmospheric environment with MPV1 $<0$ is favorable for low vortex's formation, and MPV2 exerts more impact on the SWV movement.

Figures $8(\mathrm{a})$ and $8(\mathrm{~b})$ reflected the evolution of MPV1 and MPV2 when the SWV moved from north to south along
Yunnan-Guizhou border area $\left(28-24^{\circ} \mathrm{N}\right)$. The atmosphere was moist symmetrically unstable with MPV1 > MPV2 in the absolute values, and MPV $<0$. The MPV profile along $24^{\circ} \mathrm{N}$ also showed that MPV1 $<0$ and MPV2 $>0$, and the MPV $<0$ in South China area (Figures $8(\mathrm{c})-8(\mathrm{~d})$ ). Vertical distribution of MPV indicated that the low vortex was always in the environment with the convective unstable and certain baroclinic atmosphere over the Yunnan-Guizhou 


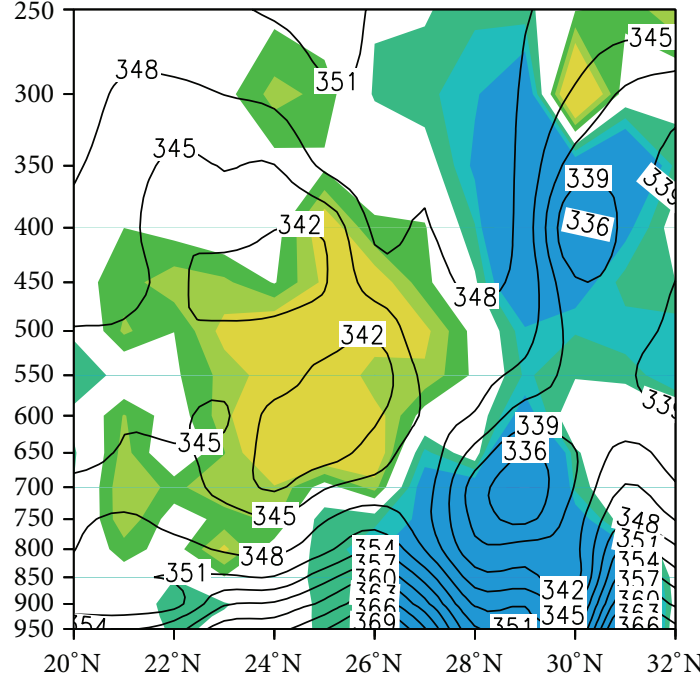

(a) 0000 UTC 11

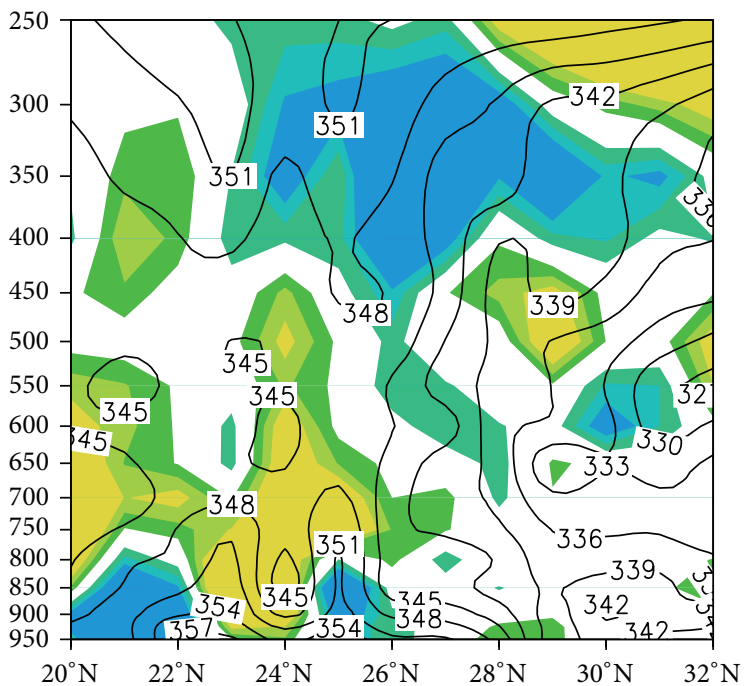

(c) 0000 UTC 12

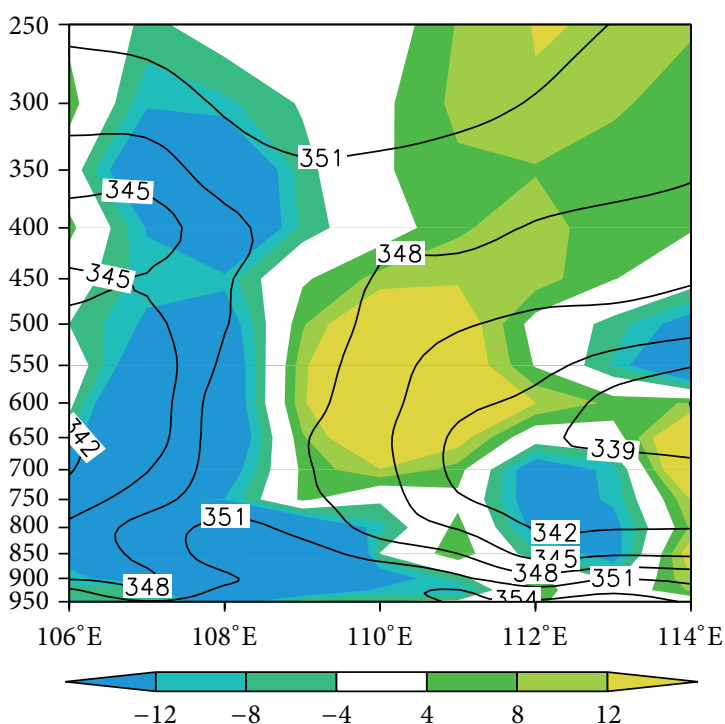

(e) 1200 UTC 12

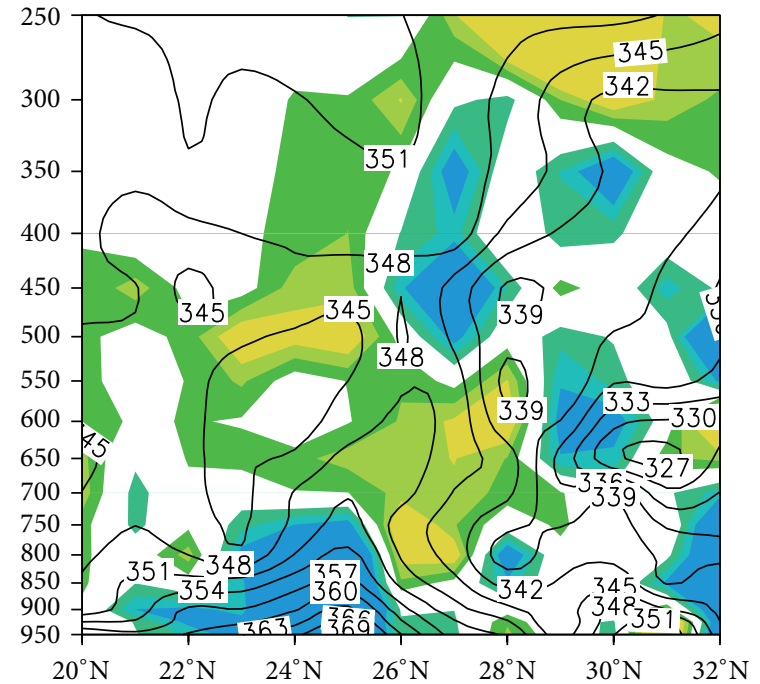

(b) 1200 UTC 11

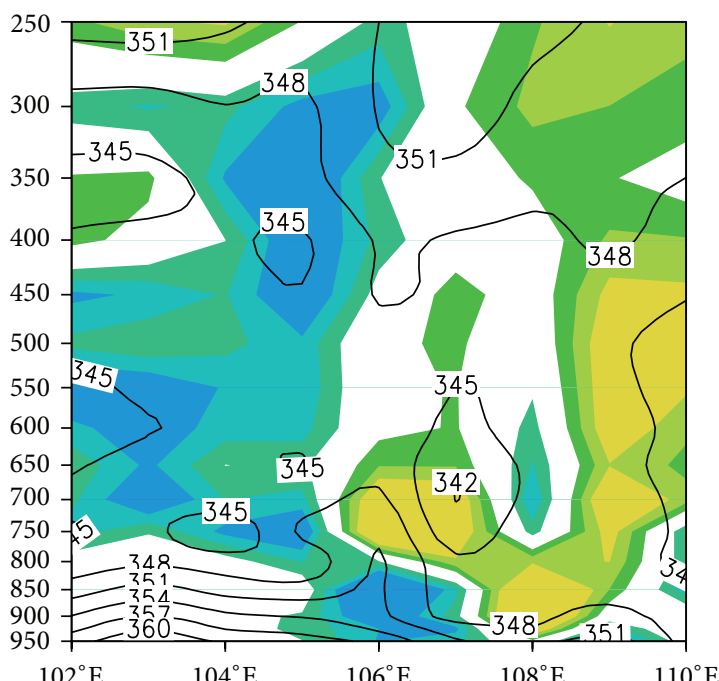

(d) 0000 UTC 12

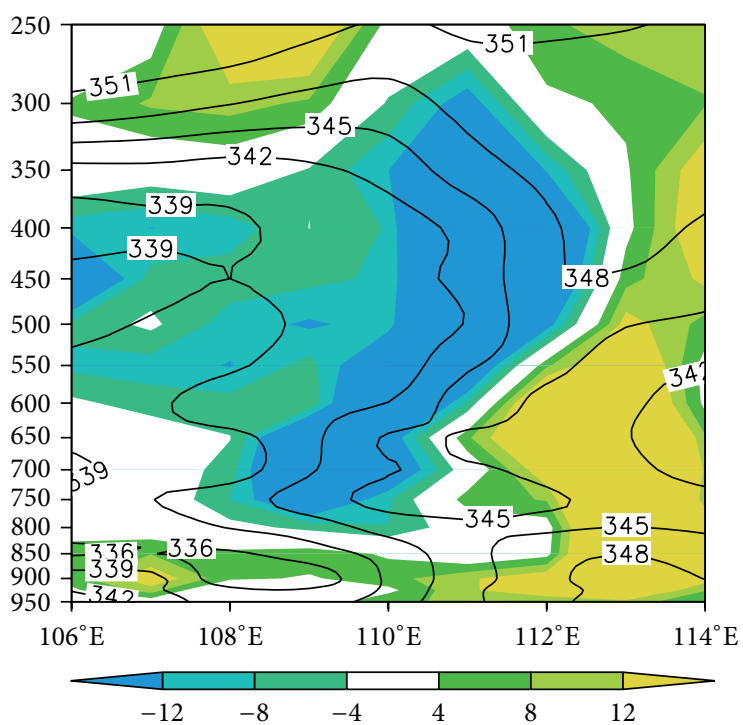

(f) 0000 UTC 13

FIgure 7: Continued. 


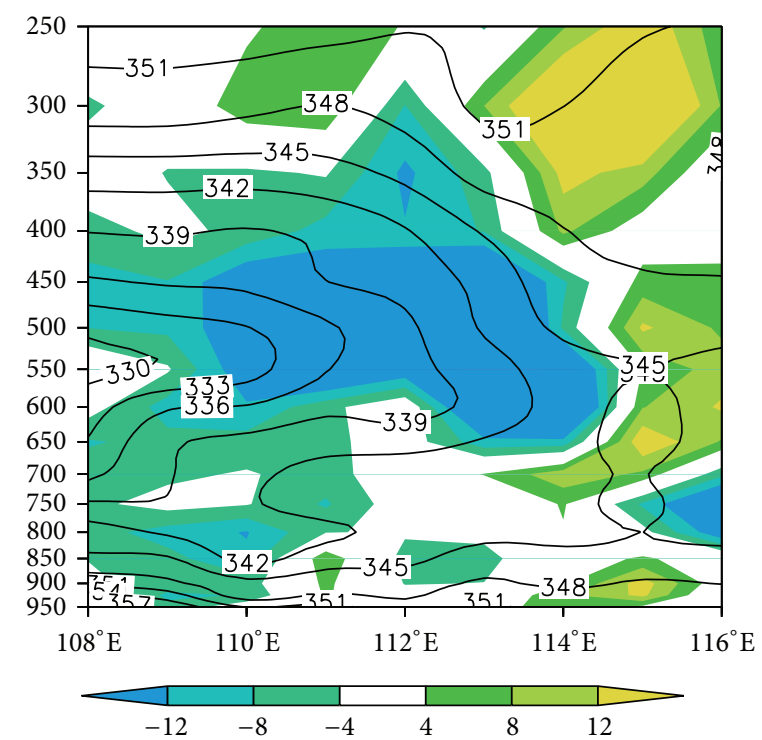

(g) 1200 UTC 13

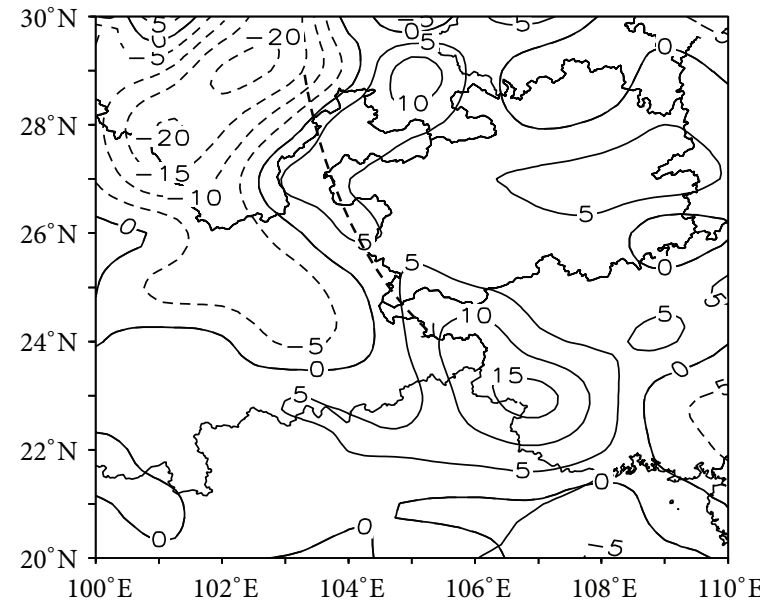

(h) $700 \mathrm{hPa}$

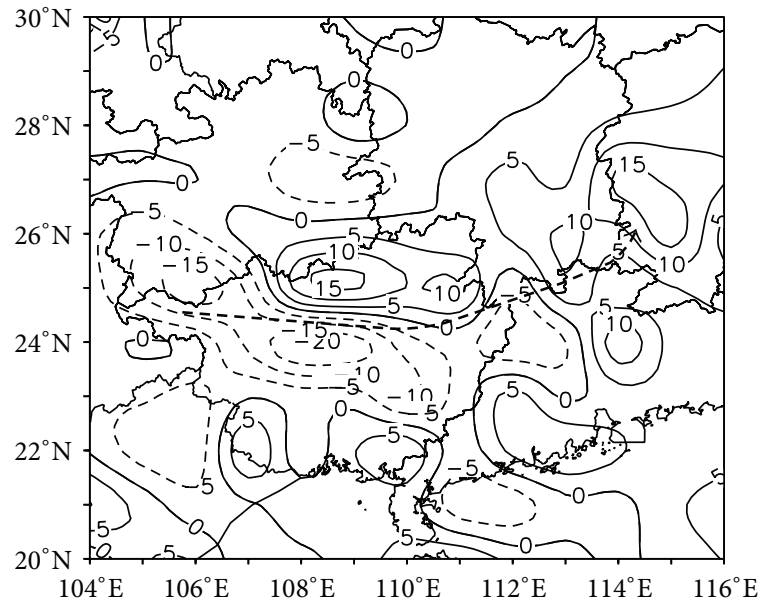

(i) $700 \mathrm{hPa}$

Figure 7: The distribution of pseudo equivalent potential temperature $\theta_{\text {se }}(\mathrm{K})$ and the advection $-\vec{V} \cdot \nabla \theta_{\text {se }}\left(\operatorname{colored}\right.$ shaded in $\left.10^{-5} \mathrm{~K} \cdot \mathrm{s}^{-1}\right)$ at the vertical sections along (a) $104^{\circ} \mathrm{E}$, (b) $105^{\circ} \mathrm{E}$, and (c) $106^{\circ} \mathrm{E}$; (d, f, and g) $25^{\circ} \mathrm{N}$ and (e) $24^{\circ} \mathrm{N}$ as well as the horizontal distribution of (h) averaged $-\vec{V} \cdot \nabla \theta_{\text {se }}$ over 18 UTC June 10 to 18 UTC June 11,2008 , and (i) averaged $-\vec{V} \cdot \nabla \theta_{\text {se }}$ over 18 UTC June 11 to 00 UTC June $13,2008$.

border area; compared to South China area, the atmospheric baroclinicity was slightly stronger in Yunnan-Guizhou area, suggesting that atmospheric baroclinicity weakened in the vortex intense development period, and the convective and moist convective instability were the important environmental conditions for the low vortex maintaining and developing. To further reveal variations of MPV during the periods of intense development, the horizontal variation of $850 \mathrm{hPa}$ MPV also was analyzed (Figure 9); a negative MPV1 center was in north Guangxi area with numerical value below -1 PVU at 1200 UTC 12 (Figure 9(a)), with the corresponding MPV2 as a positive center (Figure 9(b)); it showed that the atmosphere still had baroclinic characteristics, and MPV1 $<0$ and MPV2 > 0; the SWV can develop in this region. The absolute value of MPV1 was slightly greater than that of MPV2, indicating that convective instability was still the major condition for the vertical vorticity to increase.

The negative MPV1 center was still in Guangxi but moved northward slightly at 1800 UTC 12 (Figure 9(c)), compared with previous time point, MPV1 further increased, and positive vorticity of the low vortex reached maximum (Figure 1(b)), the values of MPV2 decreased (Figure 9(d)), to a certain extent, MPV1 had insignificant influence on the low vortex's intensity, and a positive MPV2 center also formed in Jiangxi-Hunan border area, indicating that the atmospheric baroclinicity was strong in the region and the SWV may develop towards the positive MPV2 area. At 0000 UTC 13, the range where MPV1 $<0$ and MPV2 > 0 expanded; the cyclonic wind field of SWV also expanded (Figure 4(e)). In short, under the conditions of convective instability, as long 


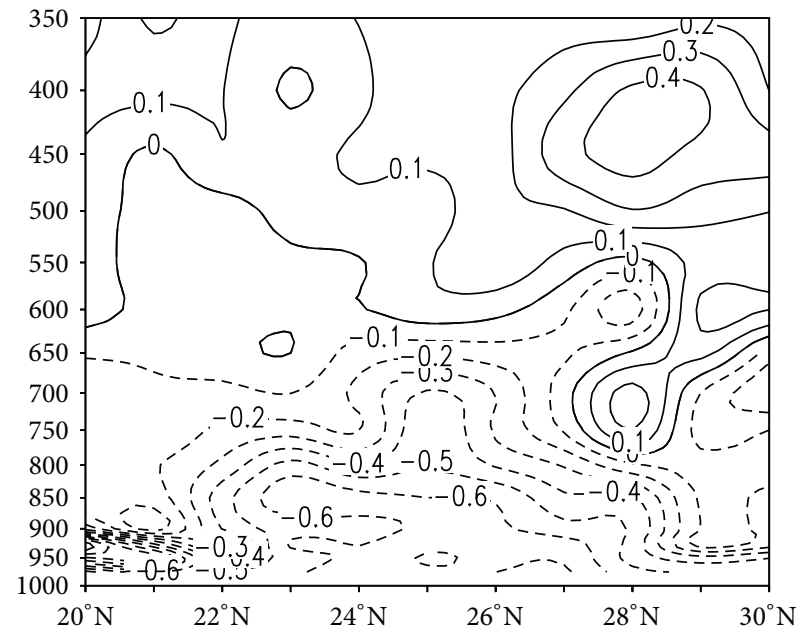

(a) MPV1 along $105^{\circ} \mathrm{E}$

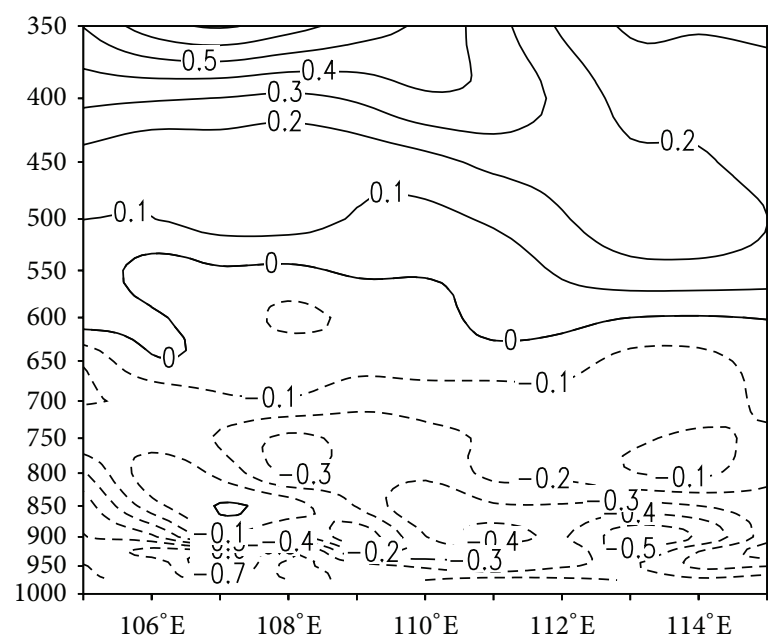

(c) MPV1 along $24^{\circ} \mathrm{N}$

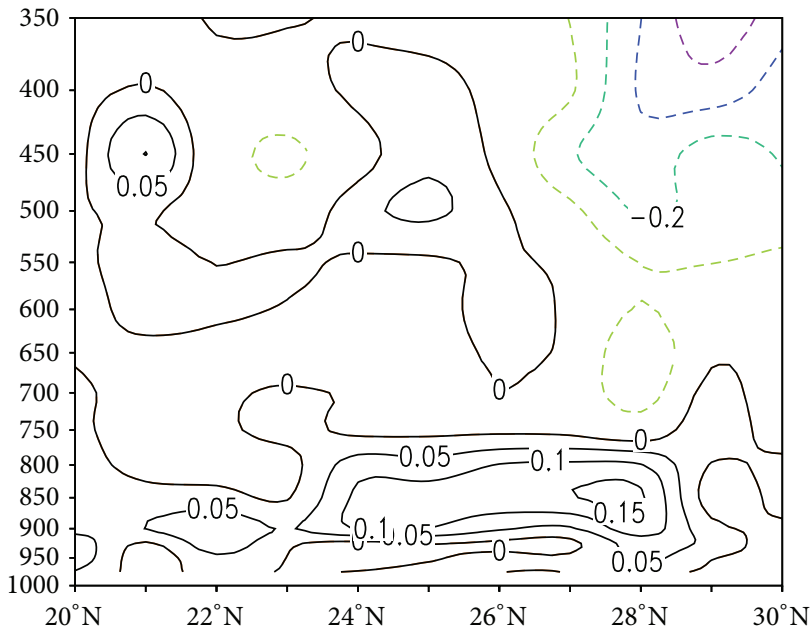

(b) MPV2 along $105^{\circ} \mathrm{E}$

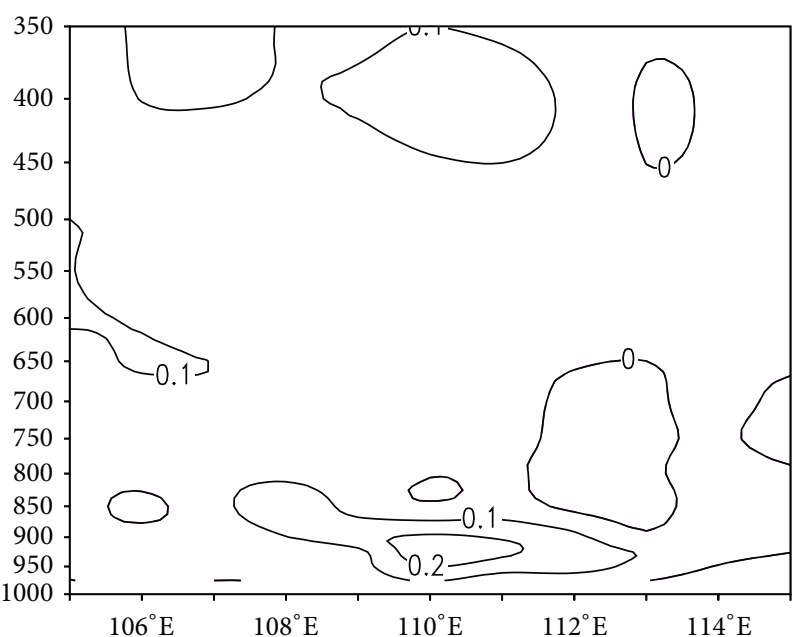

(d) MPV2 along $24^{\circ} \mathrm{N}$

Figure 8: The time-mean MPV1 and MPV2 profiles for (a, b) phases I and (c, d) II. Their unit in PVU $\left(1 \mathrm{PVU}=10^{-6} \mathrm{~m}^{2} \cdot \mathrm{K} \cdot \mathrm{s}^{-1} \cdot \mathrm{kg}^{-1}\right)$.

as MPV1 $<0$ and MPV2 $>0$, SWV could develop. MPV1 has an important influence on maintaining of vortex, MPV2 plays an important role on the movement, and it could be used as an indication signal for the movement and range variation of the low vortex. Of course, the development mechanism of the vortex is more complex than diagnosis results of MPV. The impact factors are more and still need further study. Here, on the basis of the analysis of vortex development, we further analyze the cause of rainstorm process.

\section{Physical Process on the Heavy Rainfall}

5.1. Water Vapor Flux Transport and Convergence. As largerange, long time heavy rainfall process, favorable water vapor transport is an important factor to introduce heavy rainfall, but whether water vapor can gather in one place or not is more critical.

To describe water vapor transport during the heavy rainfall, by referencing the study of Neiman et al. 2008 [30], vertically integrated water vapor fluxes (IWV) are calculated as

$$
\mathrm{IW} V=-\int_{p_{0}}^{p} \frac{1}{g} q \vec{V} d p .
$$

Furthermore, the divergence of vertically integrated water vapor fluxes (DIWV) is calculated as

$$
\text { DIWV }=-\nabla \cdot\left(\int_{p_{0}}^{p} \frac{1}{g} q \vec{V} d p\right)
$$

where $p_{0}=1000 \mathrm{hPa}, p=300 \mathrm{hPa}$, and $g$ is the acceleration of gravity.

Water vapor of the heavy rainfall mainly came from the Bay of Bengal and South China Sea (Figure 10). In the first stage of the low vortex's movement, water vapor was transported from the ocean surface of Bay of Bengal by southwest wind, IW $\overrightarrow{W V}$ values $<300 \mathrm{~kg} \cdot \mathrm{m}^{-1} \cdot \mathrm{s}^{-1}$, but DIWV values $<-40 \times 10^{-4} \mathrm{~kg} \cdot \mathrm{m}^{-2} \cdot \mathrm{s}^{-1}$ in heavy rainfall area of YunnanGuizhou border (Figures 10(a) and 10(b)), water vapor flux 


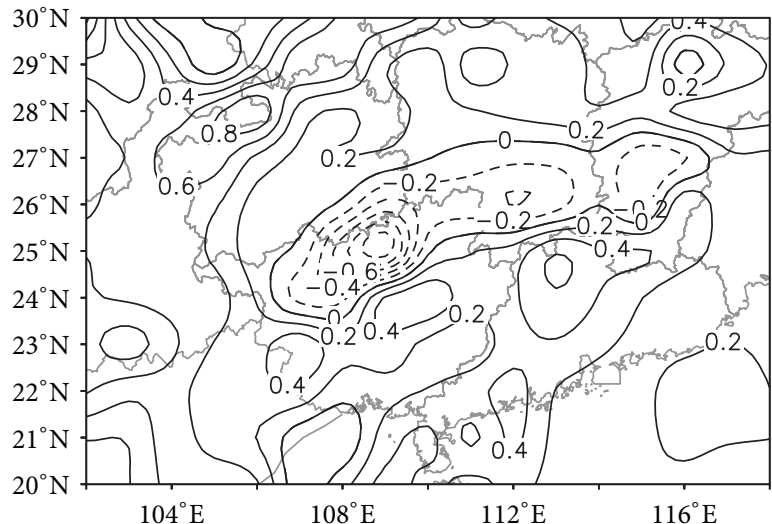

(a) MPV1 at 1200 UTC 12

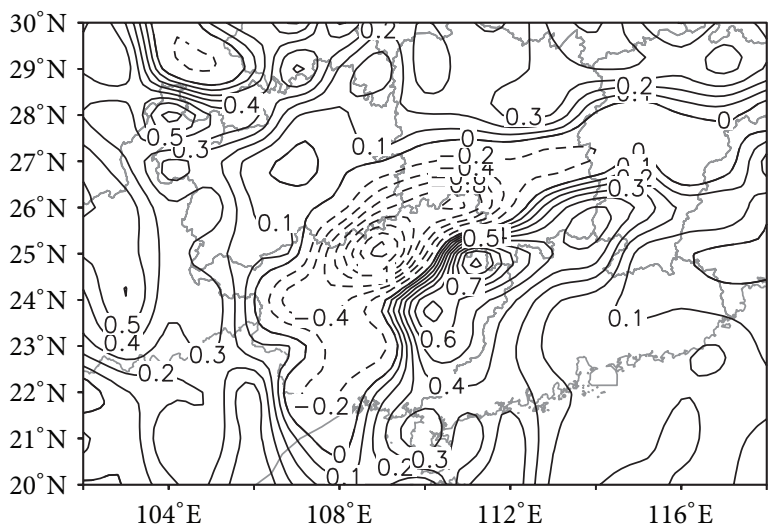

(c) MPV1 at 1800 UTC 12

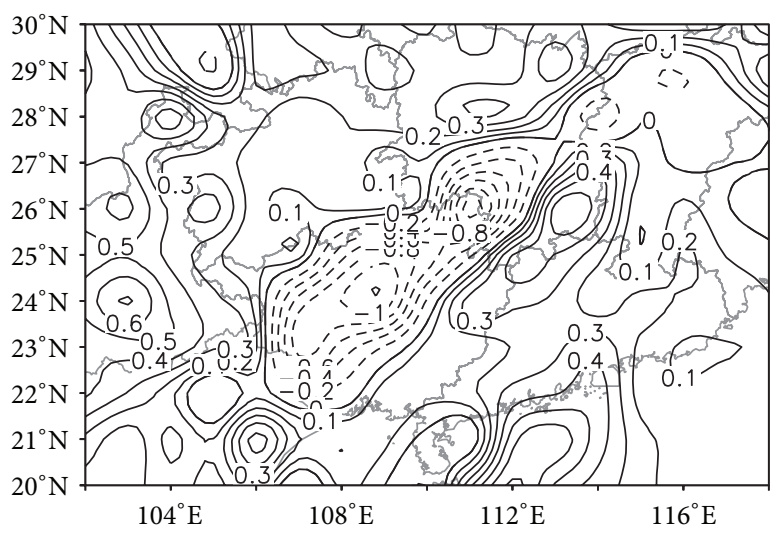

(e) MPV1 at 0000 UTC 13

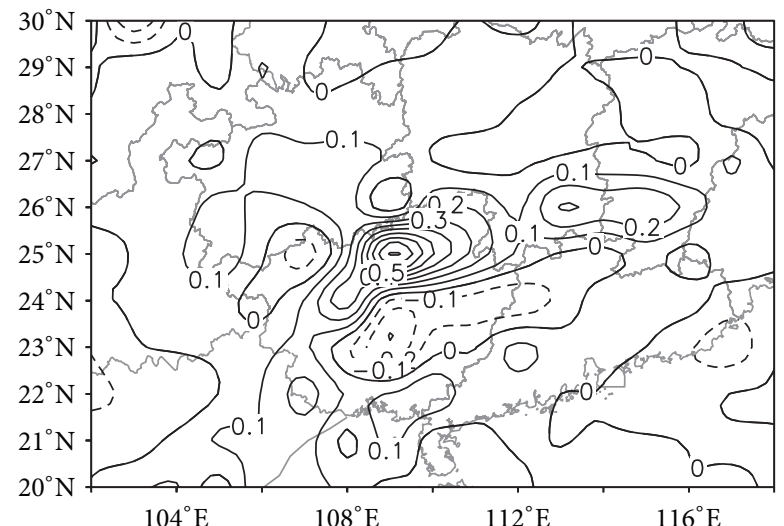

(b) MPV2 at 1200 UTC 12

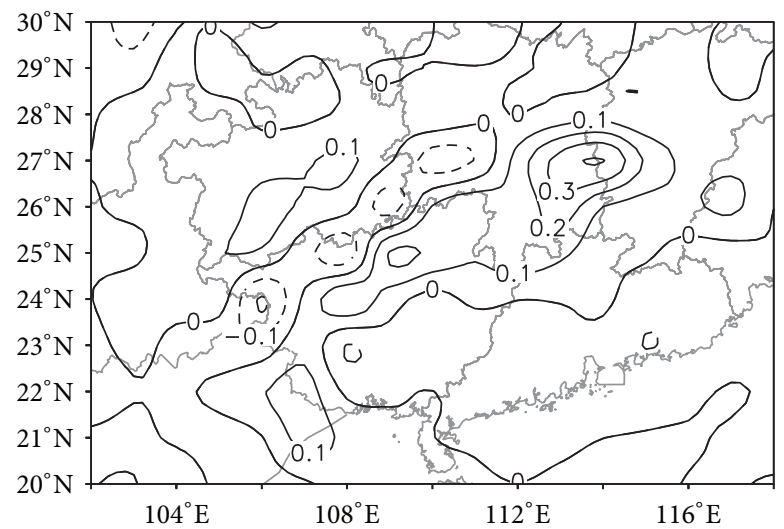

(d) MPV2 at 1800 UTC 12

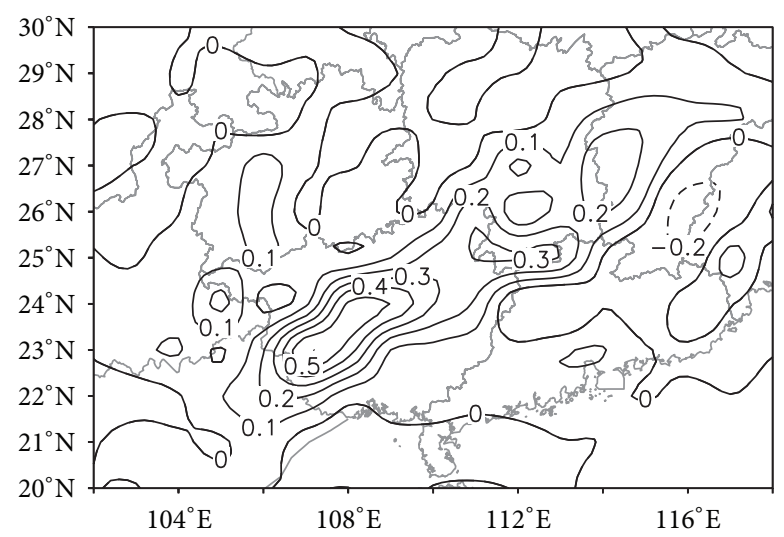

(f) MPV2 at 0000 UTC 13

Figure 9: Spatial distribution of (a, c, e) MPV1 and (b, d, f) MPV2 at $850 \mathrm{hPa}$ during the SWV development. Their unit in PVU (1 PVU = $\left.10^{-6} \mathrm{~m}^{2} \cdot \mathrm{K}^{-1} \cdot \mathrm{kg}^{-1}\right)$.

convergence was obvious. The IW $\vec{W} \mathrm{~V}$ reached $700 \mathrm{~kg} \cdot \mathrm{m}^{-1} \cdot \mathrm{s}^{-1}$, but the DIWV $>-40 \times 10^{-4} \mathrm{~kg} \cdot \mathrm{m}^{-2} \cdot \mathrm{s}^{-1}$ in South China area, and there was no obvious heavy rainfall. In the second stage, the water vapor flux convergence further strengthened in South China, not only did IW $\mathrm{WV}$ reach $700 \mathrm{~kg} \cdot \mathrm{m}^{-1} \cdot \mathrm{s}^{-1}$, but also DIWV reached the values of $-40 \sim-100 \times 10^{-4} \mathrm{~kg} \cdot \mathrm{m}^{-2} \cdot \mathrm{s}^{-1}$ (Figures 10(c) and 10(d)). According to the water vapor transport conditions at different time (Figure 11), water vapor transport of Yunnan-Guizhou border area was not as good as that in South China (Figures 11(a) and 11(b)), but its flux divergence value was negative (Figures 11(c) and 11(d)), which was favorable for converging water vapor and formation of heavy rainfall. Water vapor flux with SWV moving eastward reached $600 \mathrm{~kg} \cdot \mathrm{m}^{-1} \cdot \mathrm{s}^{-1}$ in Guangxi area during 1200 UTC 111200 UTC 12 (Figures 11(e) 11(h)), and its convergence values exceeded $-100 \times 10^{-4} \mathrm{~kg} \cdot \mathrm{m}^{-2} \cdot \mathrm{s}^{-1}$. The configuration of water 


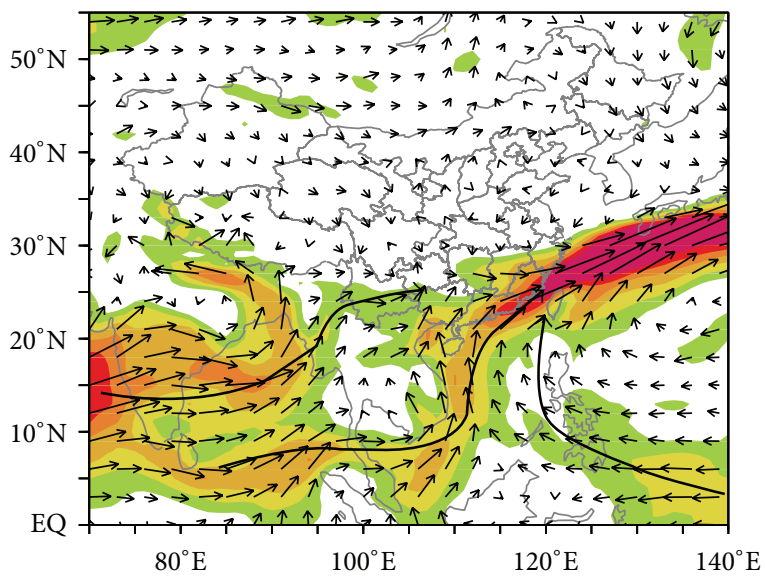

(a)

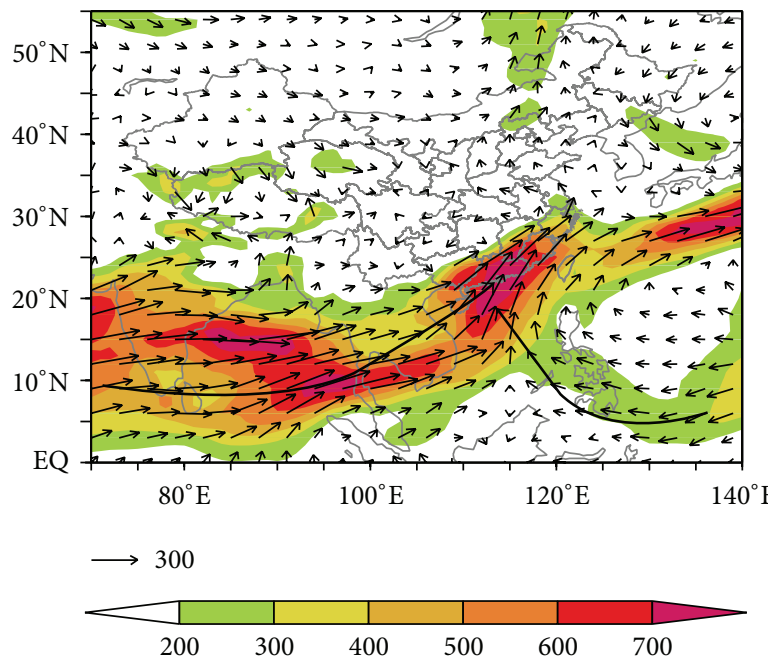

(c)

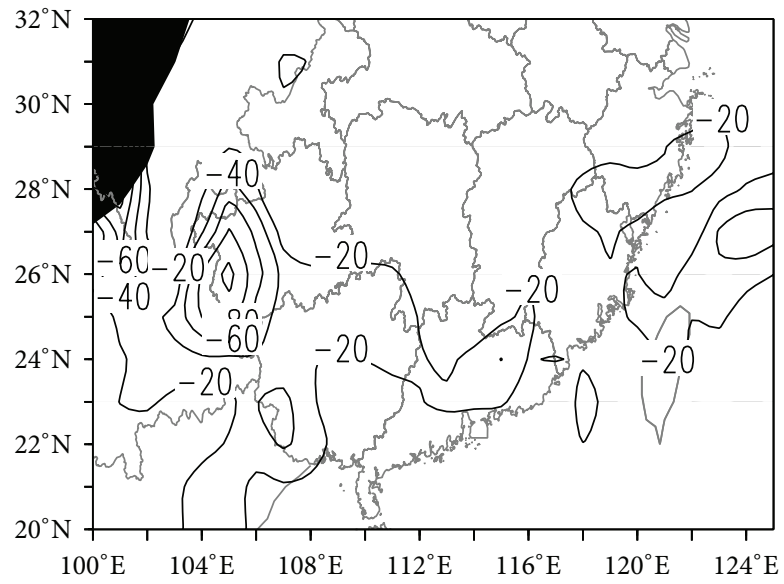

(b)

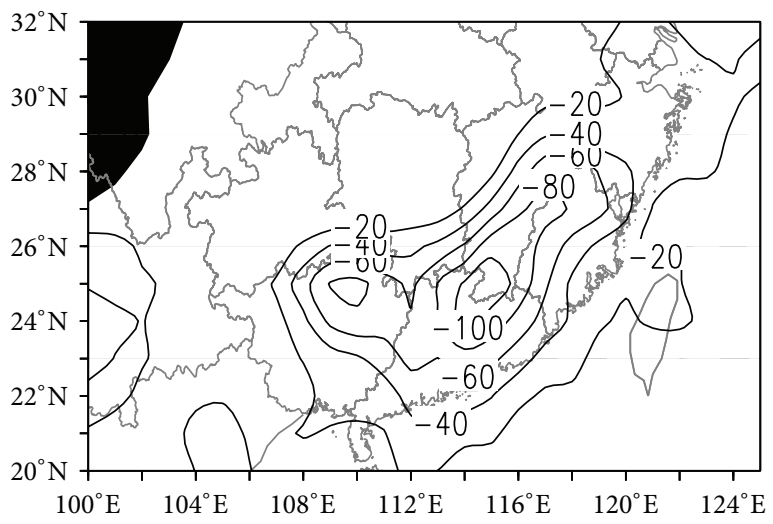

(d)

Figure 10: Distribution of water vapor transport flux vectors and strengths (color contours) integrated over $1000-300 \mathrm{hPa}\left(\mathrm{kg} \cdot \mathrm{m}^{-1} \cdot \mathrm{s}^{-1}\right)(\mathrm{a})$ during 18 UTC of June 10-18 UTC of June 11, 2008, and (c) during 18 UTC of June 11-18 UTC of June 13, 2008, as well as (b and d) distribution of water vapor flux divergence $\left(\times 10^{-4} \mathrm{~kg} \cdot \mathrm{m}^{-2} \cdot \mathrm{s}^{-1}\right)$.

vapor transport and the low vortex was very favorable and caused heavy rainfall in Guangxi and south Hunan. As of 1200 UTC 13 (Figures 11(i) and 11(j)), big values of water vapor flux was in the coastal area of South China, and the amount of water vapor flux convergence further increased, so the heavy rainfall was induced along the coast of South China. Obviously, water vapor flux convergence was related to the SWV development and movement; the positive vorticity, horizontal wind field convergence, and ascending motion intensified water vapor convergence, which then provided adequate water vapor for forming of the heavy rainfall.

5.2. MCSs Activity in SWV. The TBB could reflect the activities of MCSs. Figure 12 shows the time series of hourly satellite black body temperature (TBB) during the SWV movement. The heavy rainfall which occurred in YunnanGuizhou border area (Figures 2(a)-2(b)) resulted from the MCSs with $\mathrm{TBB}<-60^{\circ} \mathrm{C}$ at $28^{\circ} \mathrm{N}-26^{\circ} \mathrm{N}$ (Figure $12(\mathrm{a})$ ). The MCSs developed gradually and moved southwards, and
MCSs lasted for more than 8 hours. After 00UTC of June 11, 2008, the MCSs were getting weak. At 12 UTC of June 11, 2008 (Figure 12(b)), the MCSs in the vortex began to recover and turned eastwards; convective cloud systems with TBB values $<-60^{\circ} \mathrm{C}$ lasted for more than 12 hours and declined after 03UTC of June 12, 2008. After 12 UTC of June 12, 2008 (Figure 12(c)), MCSs started to strengthen and develop again for more than 6 hours. After 12 UTC of June 13, 2008 (Figure 12(d)), the convective clouds in SWV began to develop into a meso- $\alpha$ scale vortex circulation at this stage, and the clouds of low TBB value located in South China along coast where LLJ was active for longer than 10 hours with severe heavy rainfall in the area. Thus, MCSs built and then moved eastwards constantly during the heavy rainfall; these convective cloud systems intensified at night, suggesting that the vortex has obvious diurnal variation.

To describe the evolution and organizing of MCSs in each rainfall area, the TBB distribution is presented (Figure 13) at different time; two convective cloud systems MCS $_{1}$ 


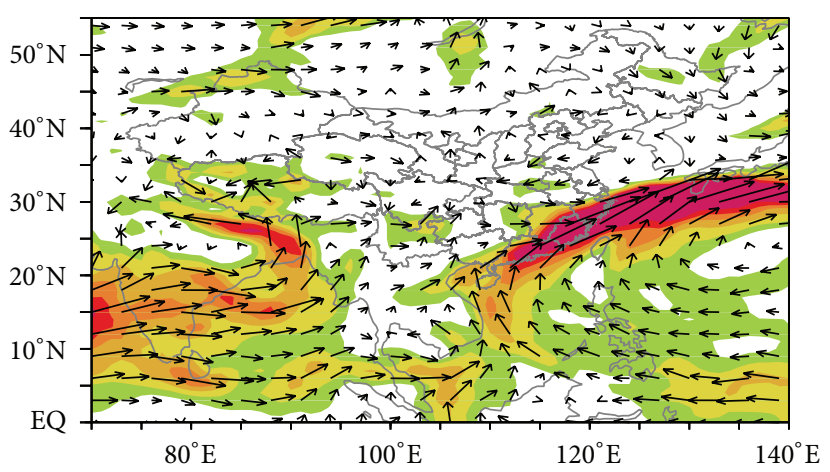

(a) 1800 UTC 10

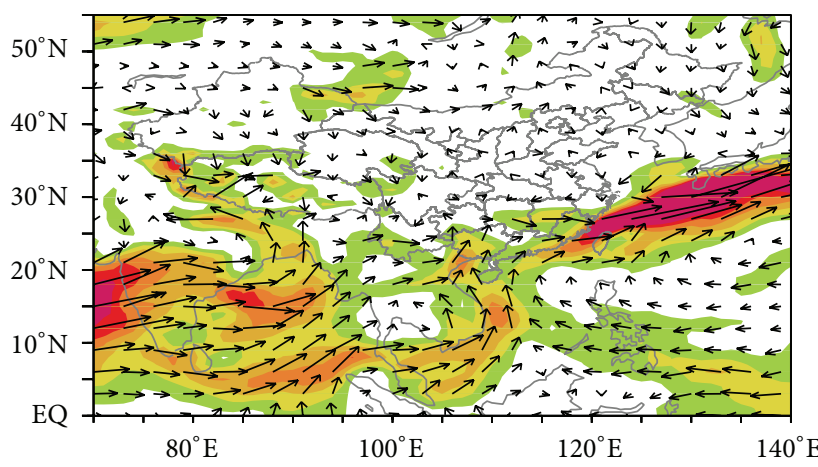

(c) 0000 UTC 11

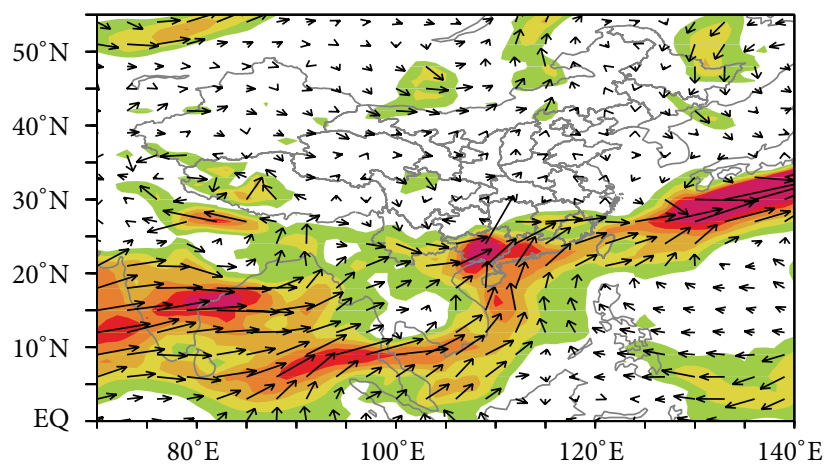

(e) 1200 UTC 11

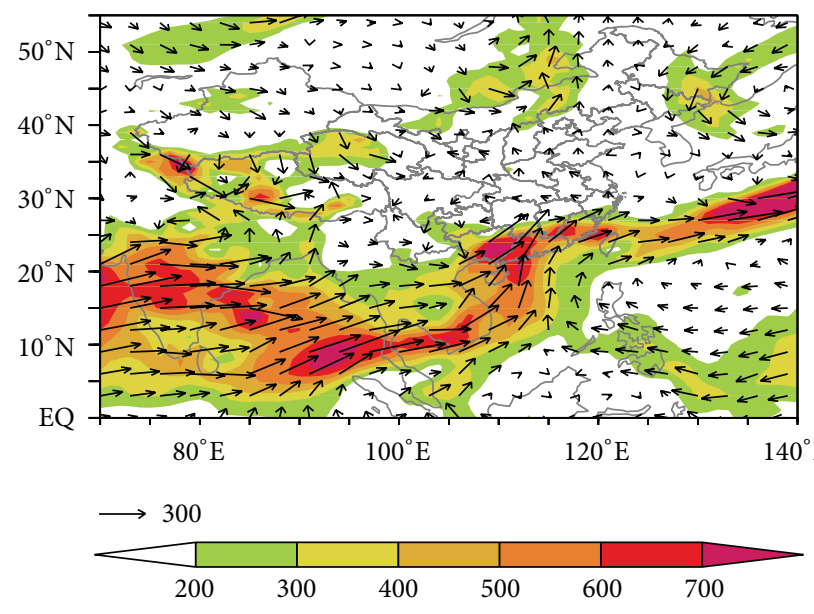

(g) 1200 UTC 12

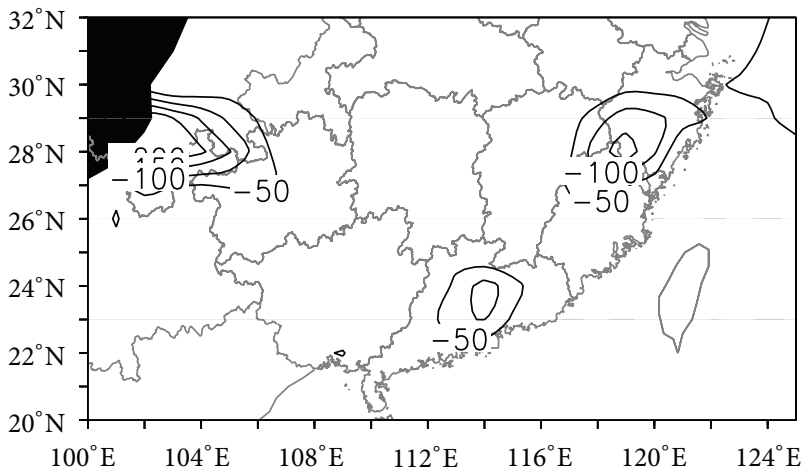

(b) 1800 UTC 10

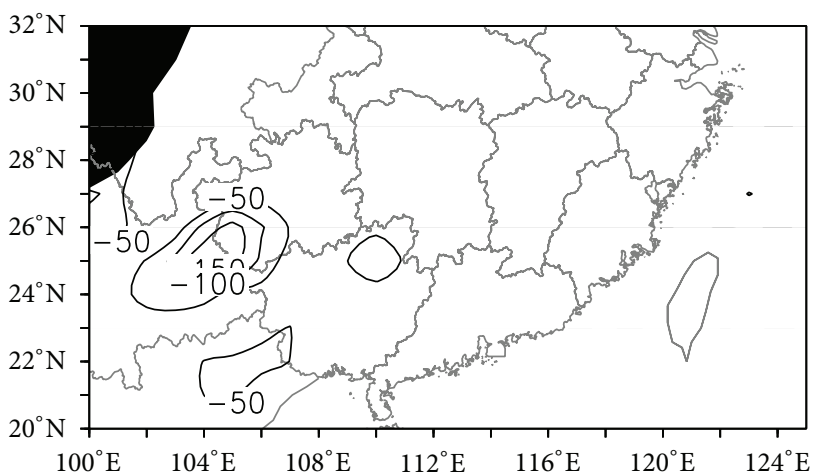

(d) 0000 UTC 11

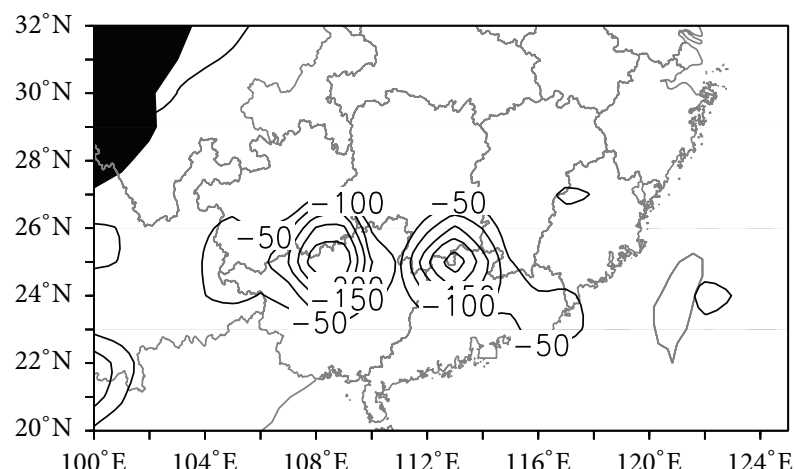

(f) 1200 UTC 11

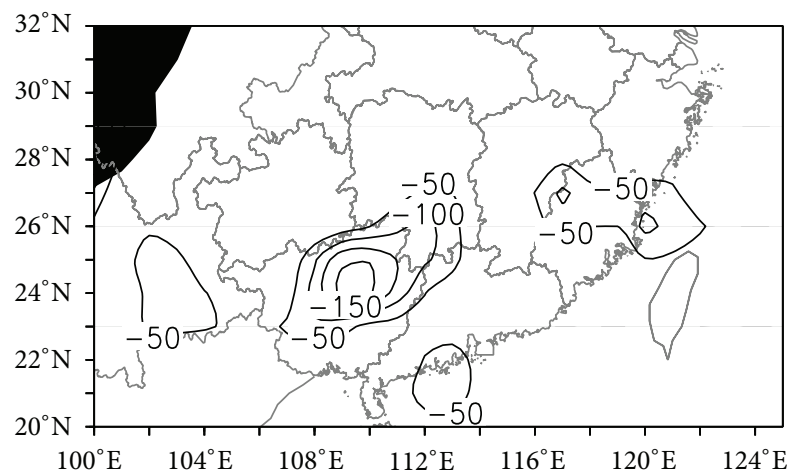

(h) 1200 UTC 12

FIGURE 11: Continued. 


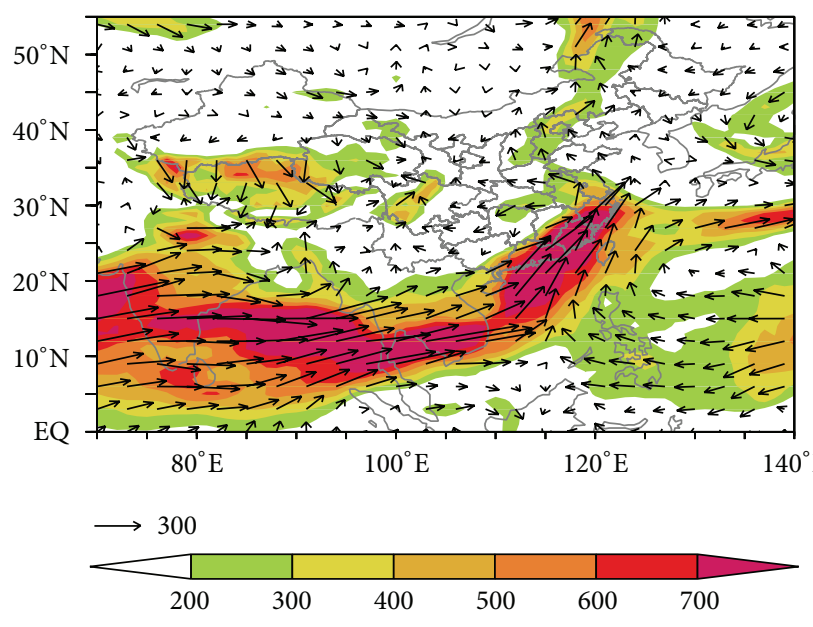

(i) 1200 UTC 13

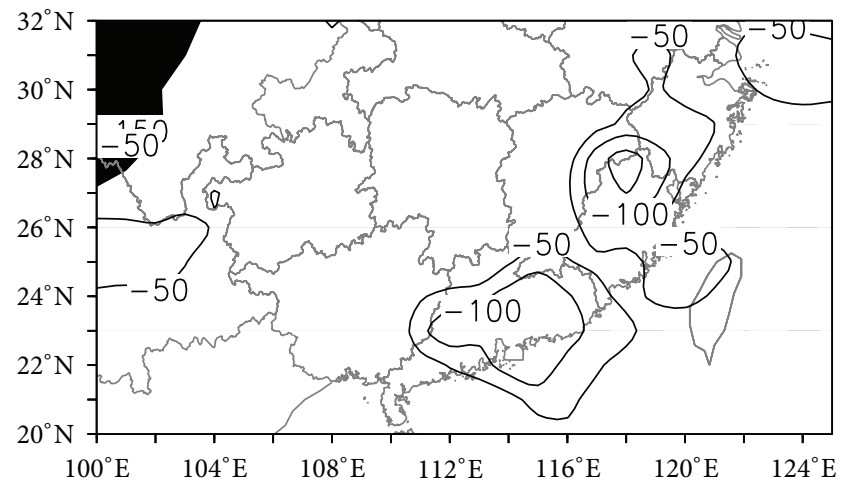

(j) 1200 UTC 13

FIgUre 11: As in Figure 10, but at different date with (a), (c), (e), (g), and (i) for the IWV , and (b), (d), (f), (h), and (j) for the DIWV.

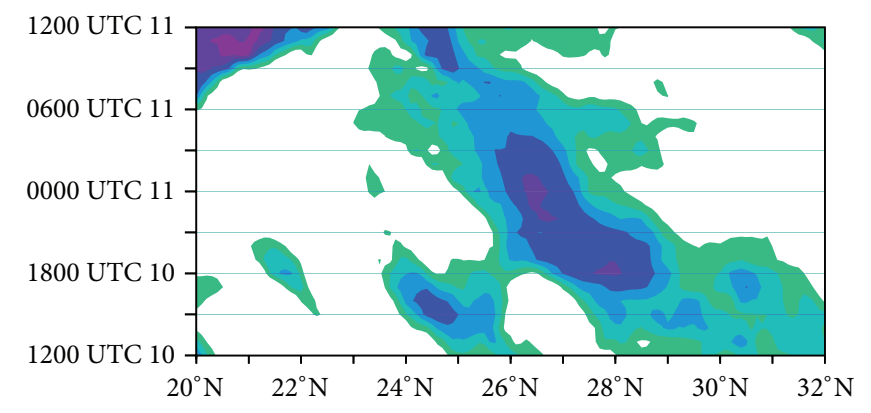

(a) Mean along $103.5-104.5^{\circ} \mathrm{E}$

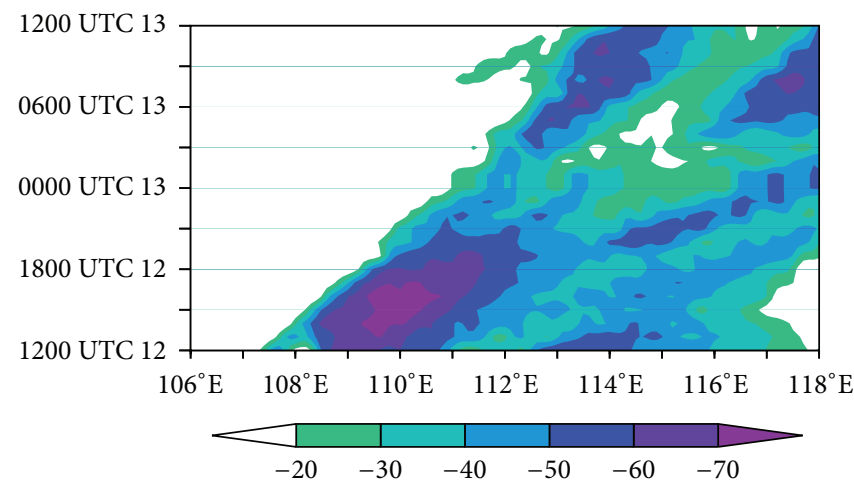

(c) Mean along $24-24.5^{\circ} \mathrm{N}$

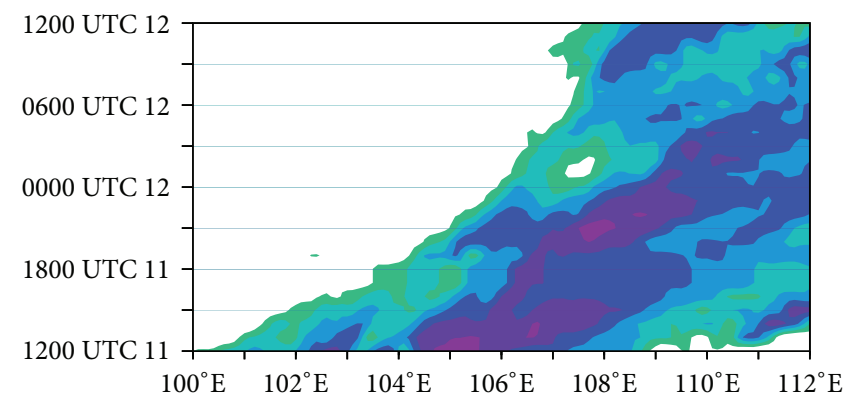

(b) Mean along $24.5-25^{\circ} \mathrm{N}$

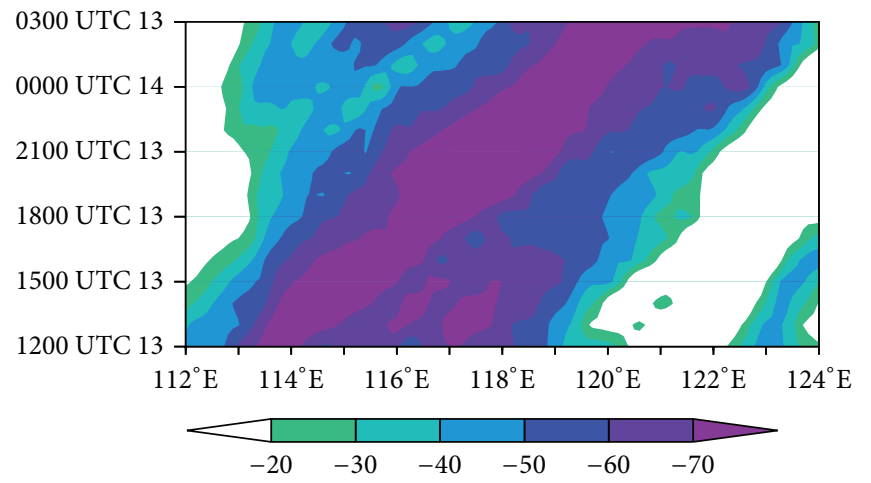

(d) Mean along $22-23.5^{\circ} \mathrm{N}$

FIGURE 12: Temporal sections of black body temperature (TBB) of the SWV cloud system in the unit of ${ }^{\circ} \mathrm{C}$.

and $\mathrm{MCS}_{2}$ ) were in Yunnan-Guizhou border area when the low vortex formed (Figure 13(a)), at 1900 UTC 10 (Figure 13(b)), $\mathrm{MCS}_{1}$ maintained in south Sichuan Plateau, while $\mathrm{MCS}_{2}$ weakened in Yunnan-Guizhou border, by 00UTC 11 (Figure 13(c)), MCS $_{1}$ moved southward slightly and $\mathrm{MCS}_{2}$ disappeared, and $\mathrm{MCS}_{1}$ also disappeared at 06UTC 11 (Figure 13(d)). MCSs lasted for more than 8 hours in this phase and induced the heavy rainfall in south Sichuan Plateau and Yunnan-Guizhou border area (Figures 2(a) and 2(b)). As of 0900 UTC 11 (Figure 13(e)), MCSs activities began to occur in Yunnan-Guizhou region and west Guangxi again; there were two mesoscale convective systems $\left(\mathrm{MCS}_{3}\right.$ and $\mathrm{MCS}_{4}$ ) in northwest Guangxi, by 13 UTC 11 (Figure 13(f)), $\mathrm{MCS}_{3}$ and $\mathrm{MCS}_{4}$ merged into $\mathrm{MCS}_{5}$ in west Guangxi and started to develop intensely (Figure 13(g)); it gradually moved eastward and weakened at 03UTC 12 (Figure 13(h)); in this phase, the MCSs lasted for more than 10 hours and caused severe heavy rainfall in Guangxi (Figures 2(b) and 2(c)). 


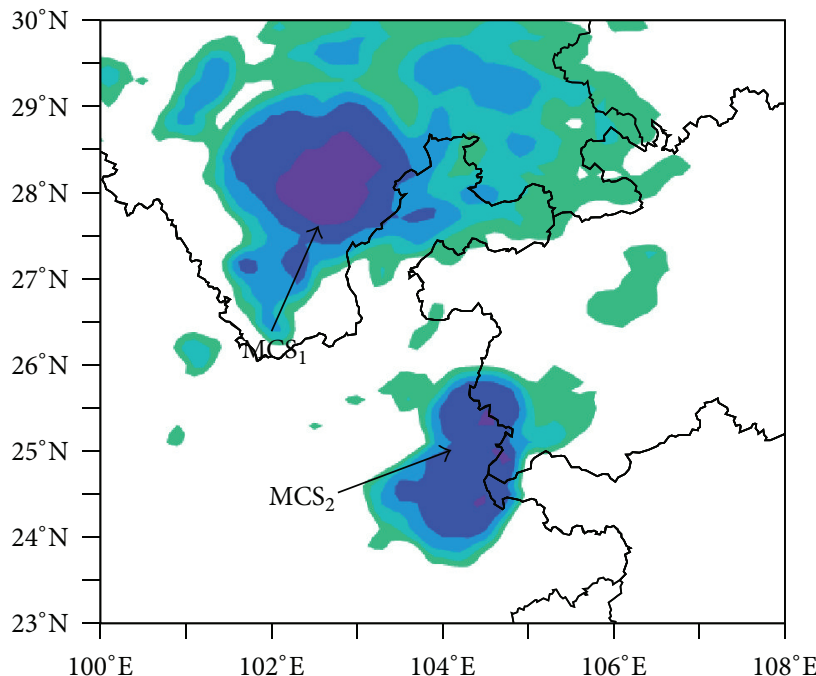

(a) 1600 UTC 10

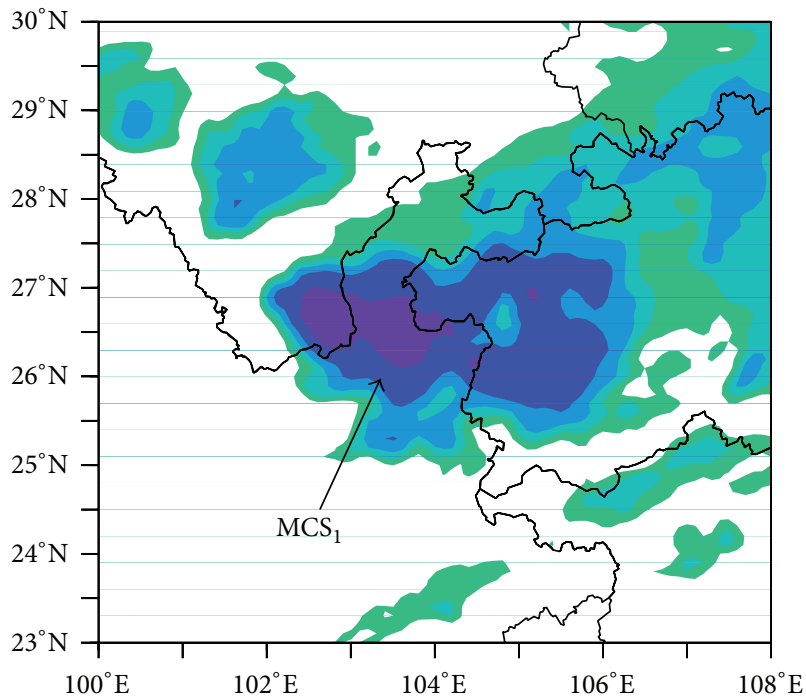

(c) 0000 UTC 11

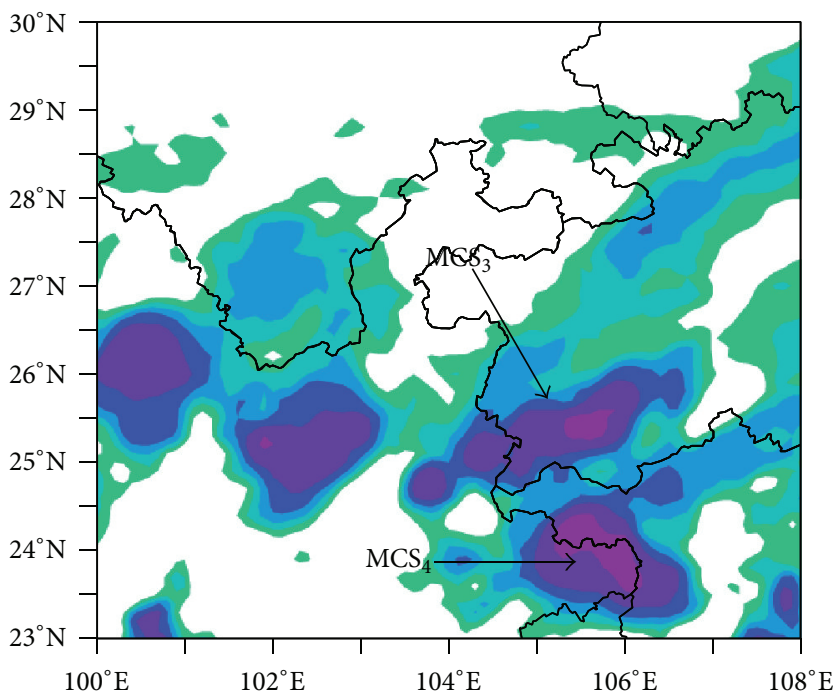

(e) 0900 UTC 11

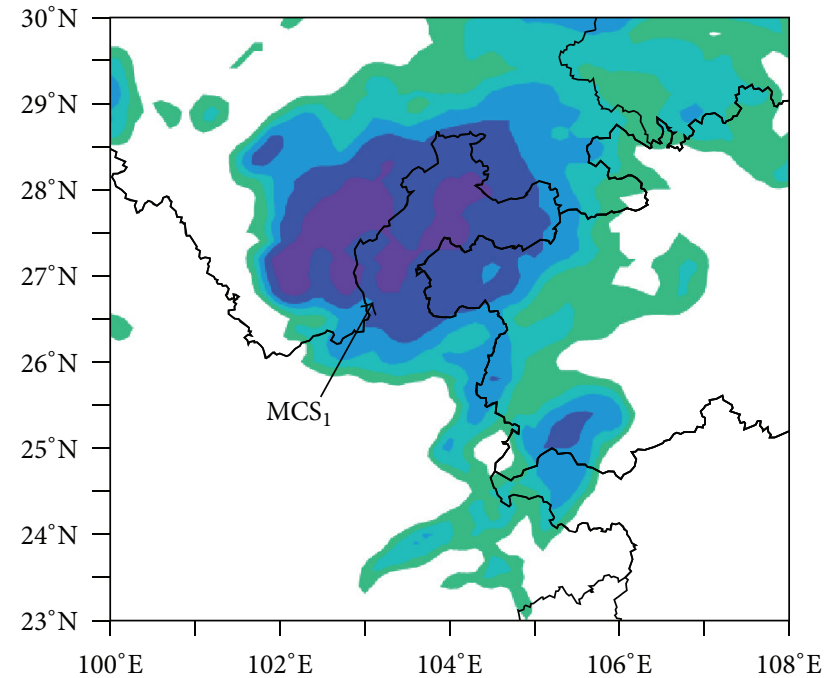

(b) 1900 UTC 10

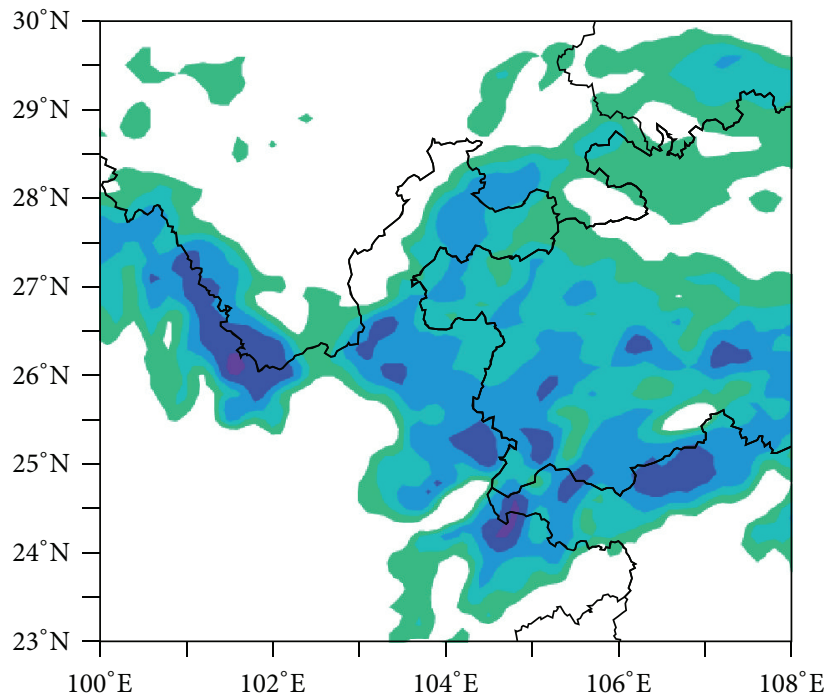

(d) 0600 UTC 11

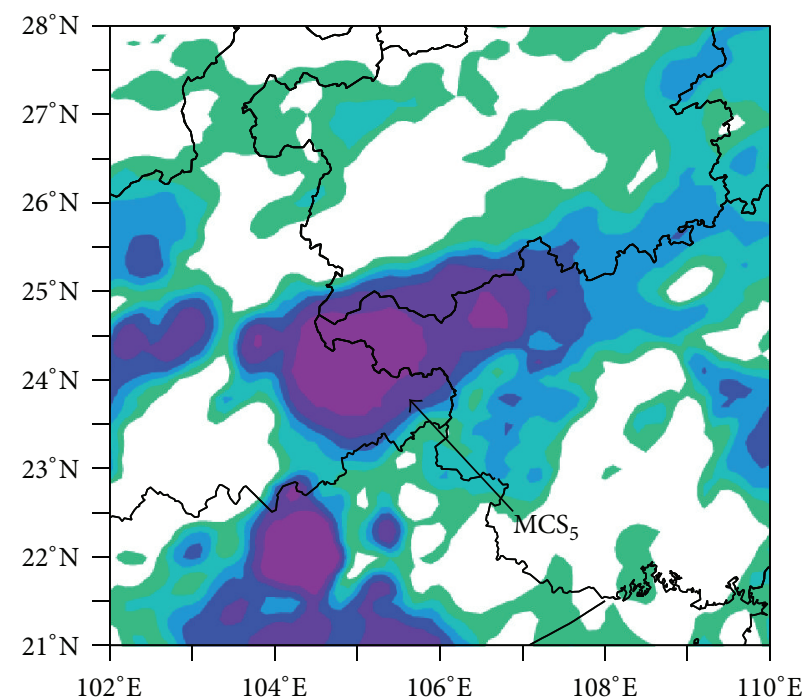

(f) 1300 UTC 11

Figure 13: Continued. 


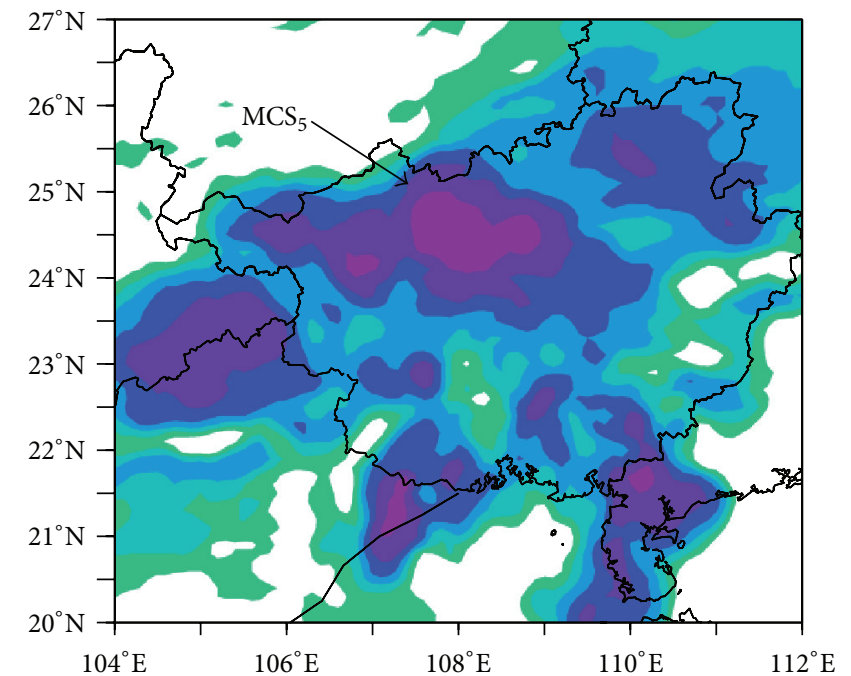

(g) 2100 UTC 11

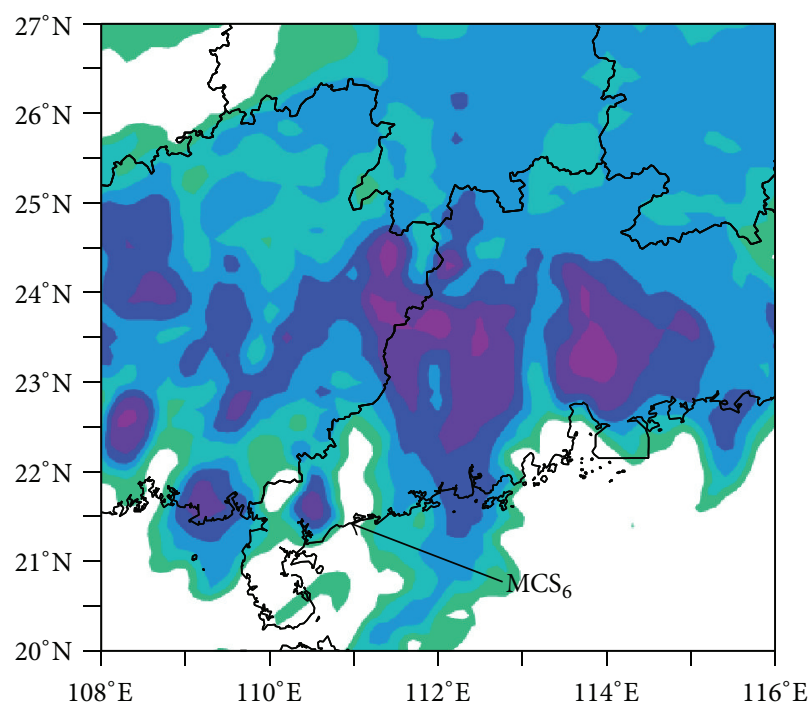

(i) 0900 UTC 12

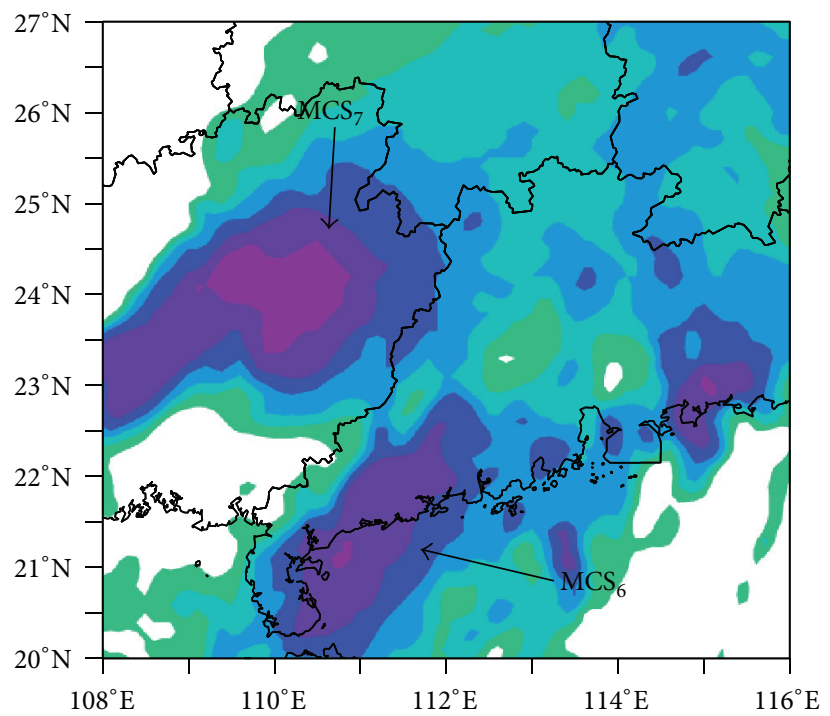

(k) 1600 UTC 12

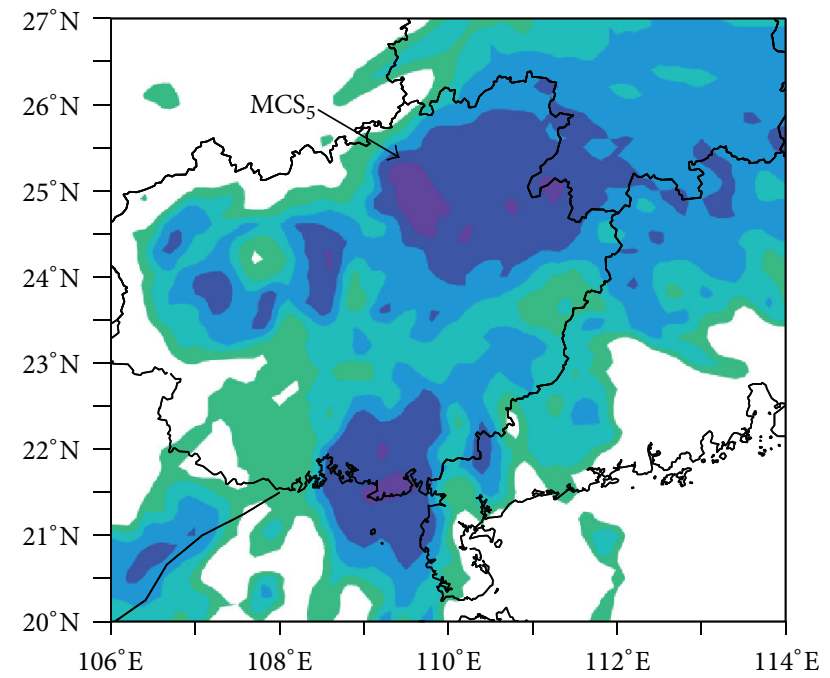

(h) 0300 UTC 12

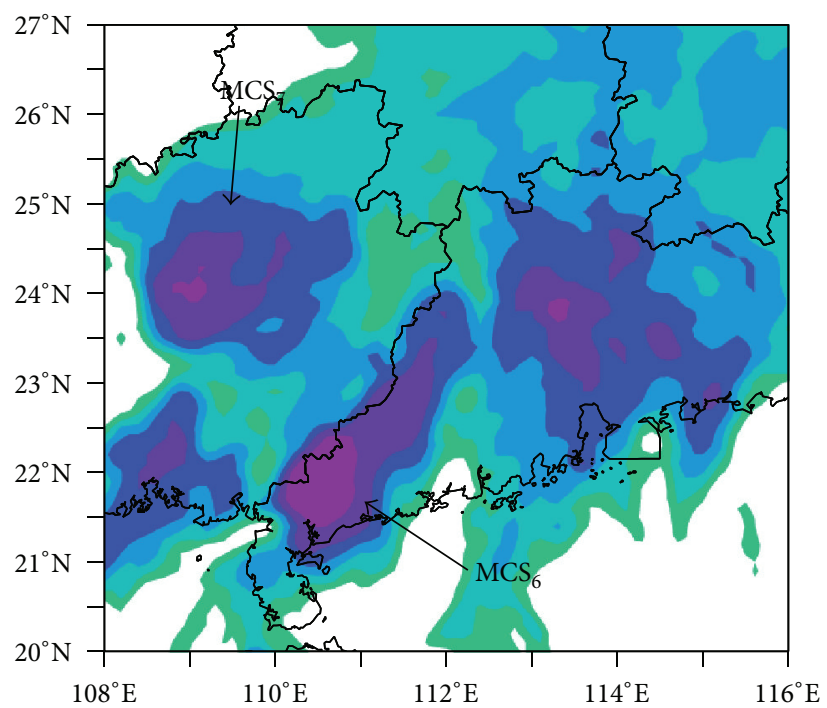

(j) 1200 UTC 12

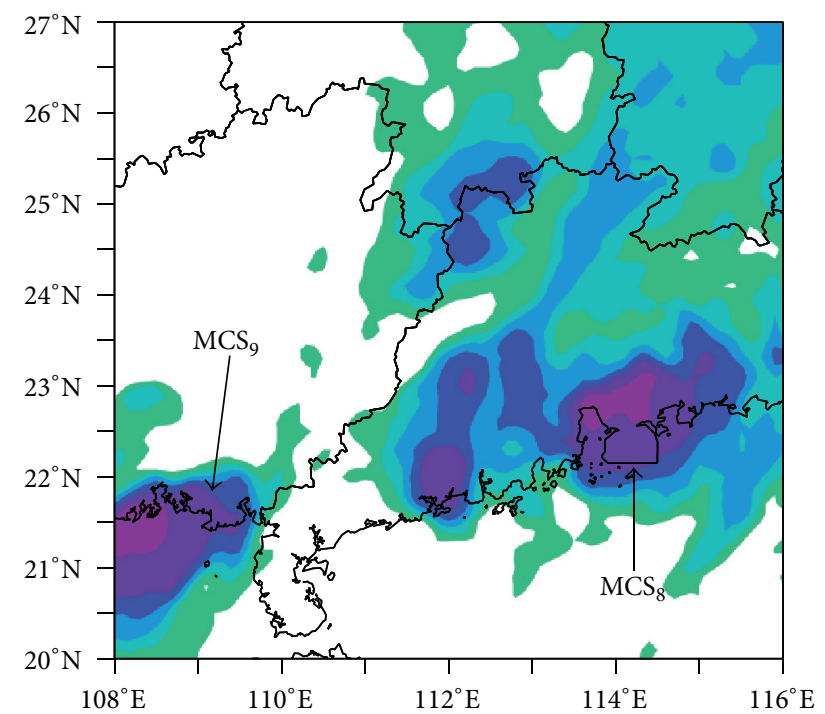

(1) 0100 UTC 13

Figure 13: Continued. 


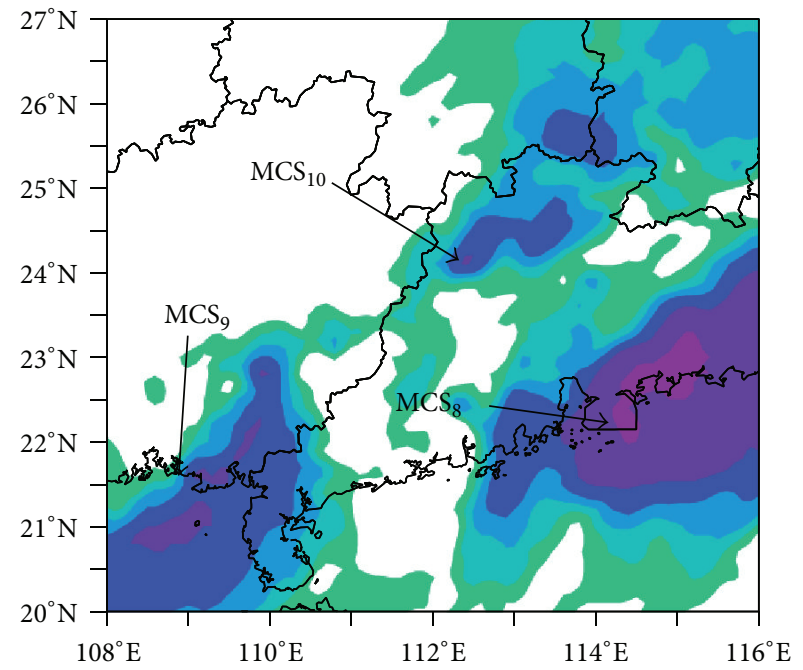

(m) 0400 UTC 13

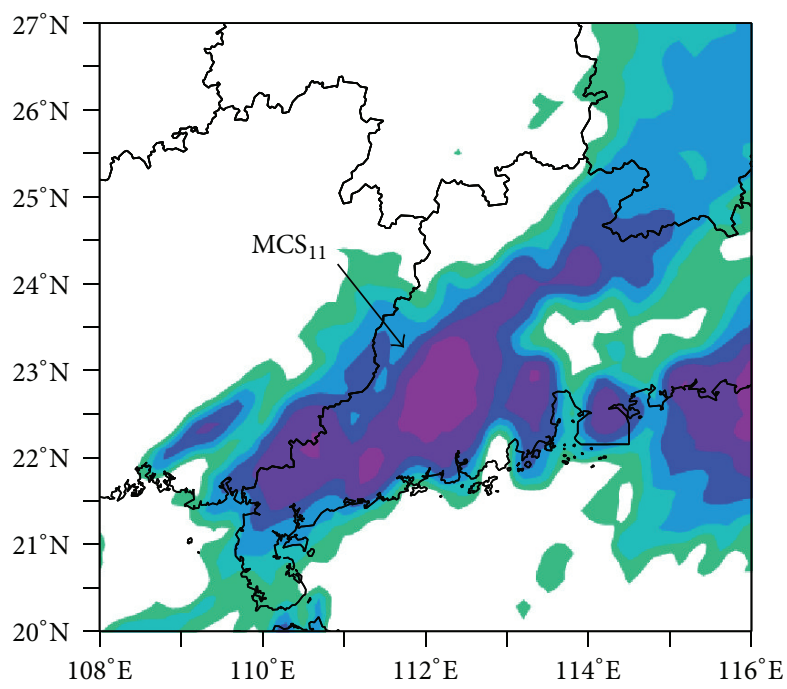

(o) 0800 UTC 13

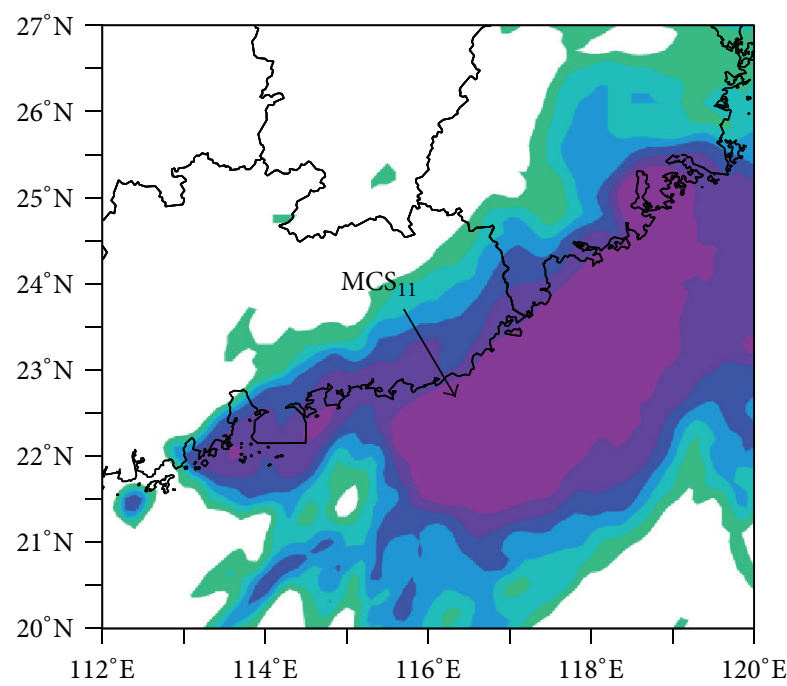

(q) 2000 UTC 13

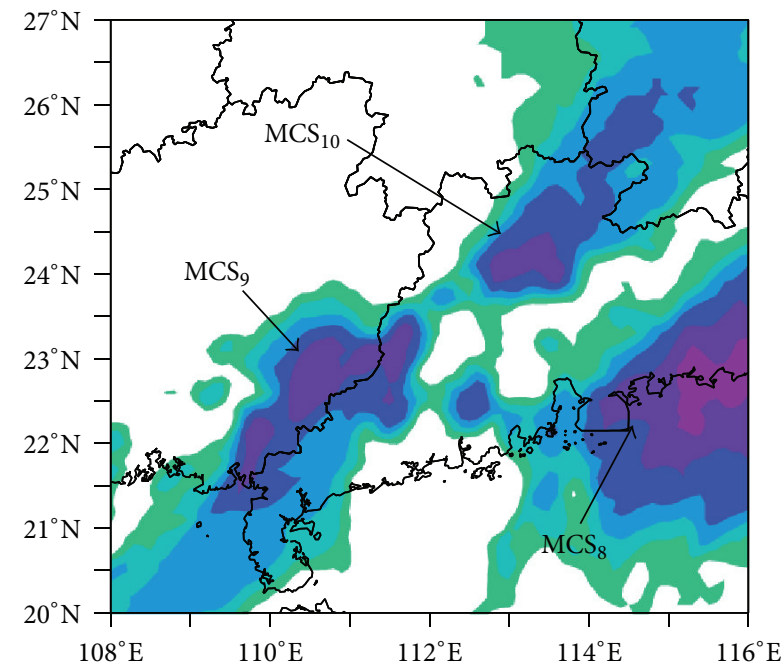

(n) 0600 UTC 13

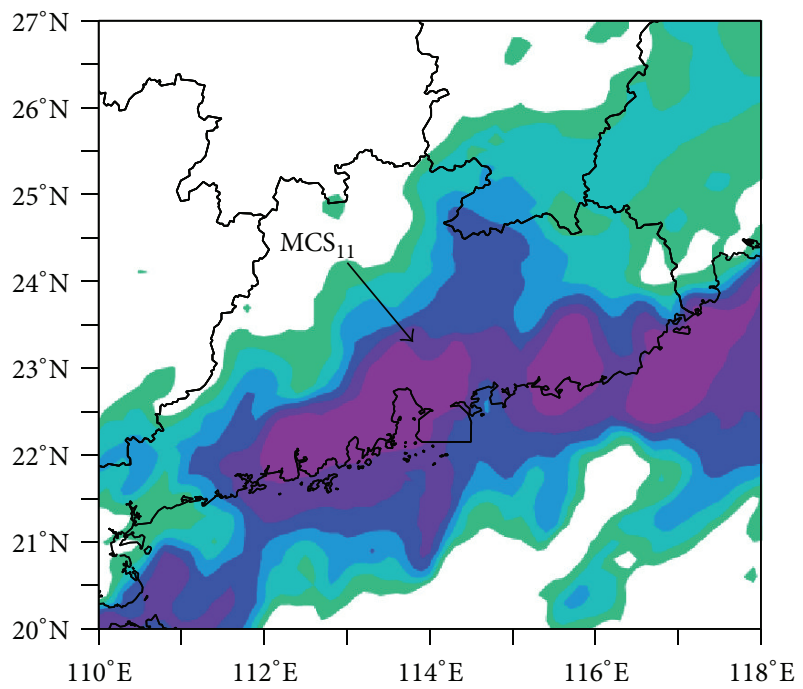

(p) 1200 UTC 13

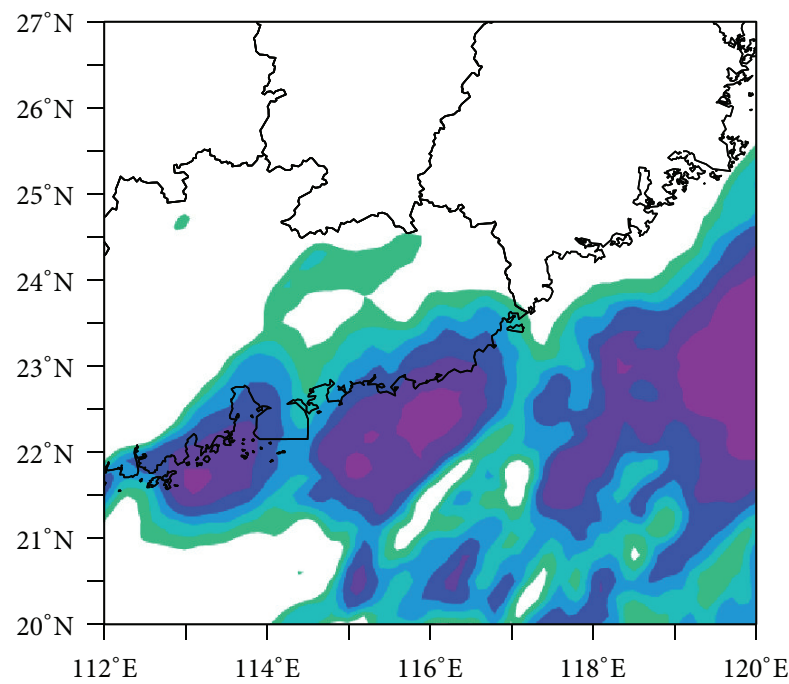

(r) 0200 UTC 14

FIgURE 13: Horizontal distribution of TBB $\left({ }^{\circ} \mathrm{C}\right)$ from June 10-14, 2008. 
At 09UTC 12 (Figure 13(i)), new MCSs started to develop in South China, among which $\mathrm{MCS}_{6}$ was a new convective system which was worth paying attention to; $\mathrm{MCS}_{6}$ developed intensely while $\mathrm{MCS}_{7}$ formed at 1200 UTC 12 (Figure 13(j)); at 16UTC 12 (Figure 13(k)), $\mathrm{MCS}_{7}$ strengthened in Guangxi area and $\mathrm{MCS}_{6}$ began to weaken in Guangdong area, where $\mathrm{MCS}_{8}$ and $\mathrm{MCS}_{9}$ began to form. By 04UTC 13 (Figure 13(m)), not only were there the stronger $\mathrm{MCS}_{8}$ and $\mathrm{MCS}_{9}$, but also a new $\mathrm{MCS}_{10}$ lasted until 08UTC 13 (Figure 13(o)), the three MCSs merged into $\mathrm{MCS}_{11}$. MCS 11 kept developing until 02UTC 14 (Figure 13(r)) and resulted in heavy rain in Guangdong and coast areas (Figure 2(d)).

Thus, along with SWV movement and development, combined with warm LLJ, MCSs continuously emerged and developed toward the rainfall areas; then continuous heavy rain was induced in South China. As seen from the evolution and organization characteristics of MCSs, they had various activities, for example, stably developing in the same area, consistently moving toward the same region and merging, moving, and developing individually. In addition, MCSs exhibited distinctive daily variation generally; MCSs emerged around late afternoon, began to develop intensely during night, and weakened in daytime. Their life cycles are up to 10 hours nearly with TBB values $<-60^{\circ} \mathrm{C}$ and meso- $\beta$ scale features. Furthermore, the daily variation of MCSs is closely related to daily variation of SWV.

\subsection{Diagnostic Analysis of Heavy Rainfall Area. As a cyclonic} vortex, the SWV exhibits distinctive ascending motion and positive vorticity features with the MCSs triggering heavy rainfall. The integrated effect of low vortex and water vapor is further investigated with the moist helicity divergence. Considering that low vortex and water vapor flux convergence are mainly concentrated in the lower troposphere, the analysis was conducted at $700 \mathrm{hPa}, 850 \mathrm{hPa}$, and $925 \mathrm{hPa}$ (Figure 14). On the first day (Figures 14(a), 14(b), and 14(c)), $700 \mathrm{hPa}$ positive moist helicity divergence was centered in south Sichuan Plateau caused by the SWV reaching $150 \times$ $10^{-11} \mathrm{~Pa} / \mathrm{s}^{3}$. The moist helicity divergences at 850 and $950 \mathrm{hPa}$ were in South China on the south side of the Yangtze River valley caused by shear line. On the second stage (Figures 14(d), 14(e), and 14(f)) and third day (Figures 14(g), 14(h), and 14(i)), the positive moist helicity divergence was in Guangxi province with values exceeding $640 \times 10^{-11} \mathrm{~Pa} / \mathrm{s}^{3}$, especially at $700 \mathrm{hPa}$ and $850 \mathrm{hPa}$. This indicates that the combined effect of low vortex and water vapor further strengthened and caused heavy rainfall in the area with large moist helicity divergence. On the fourth day (Figures 14(j), 14(k), and 14(l)), the positive moist helicity divergence was in South China along the coast, especially larger divergence value at $850 \mathrm{hPa}$ and $925 \mathrm{hPa}$. Evidently, the distribution of positive moist helicity divergence was consistent with the distribution of heavy rainfall areas, implying that the heavy rainfall areas could be identified by the variation of moist helicity divergence.

\section{Conclusions}

In this study, we analyzed the SWV activity and heavy rainfall process which occurred in South China during June 11-14, 2008. The following conclusions were drawn from this case study.

(1) This heavy rainfall was formed in the SWV movement and development. The SWV movement was steered with both the strong divergence area of $250 \mathrm{hPa}$ ULJ and the strong ascending motion in front of $500 \mathrm{hPa}$ westerly trough. When the ULJ moved southwards and westerly troughs were fluctuant, it was conducive to low vortex move southwards. The eastward movements of the ULJ and westerly trough were the favorable circulation pattern for the low vortex movement.

(2) Vertical wind shear, deep positive vorticity, and vertical ascending motion lead to a large $\mathrm{SRH}$, where the environmental vorticity was continuously transferred to the SWV with the stronger rotations and ascending motion. High SRH is conducive to the SWV development.

(3) The $\theta_{\text {se }}$ advection distribution was associated with the SWV evolution. Cold $\theta_{\text {se }}$ advections drove the low vortex SWV to move towards warm area. When the cold advection receded or vanished, the SWV weakened or disappeared.

(4) With the combined dynamic and thermodynamic effects, the moist barotropic (MPV1) and moist baroclinic (MPV2) of low-level atmosphere moist potential vorticity both played important roles in the low vortex's movement and development. The environment where MPV1 $<0$ is favorable for low vortex's formation, and MPV2 has an important influence on low vortex's movement.

(5) The MCSs were triggered by the SWV, resulting in the heavy rainfall. Water vapor was transported to the heavy rainfall areas together with the persistent MCSs activity over the SWV region, and their long-lasting frequent movements leading the severe heavy rainfall.

In addition, the diagnostic analysis demonstrated that the MHD can be a good indicator for identifying heavy-rainfall areas, as it takes into consideration both low vortex dynamics and water vapor effect. Greater positive helicity divergence often corresponds to heavy rainfall area; therefore, the MHD could be used for diagnosing heavy rain area, but it is noted that prognostic value of MHD remains to be proven by more heavy rain examples.

\section{Conflict of Interests}

The authors declare that there is no conflict of interests regarding the publication of this paper. 


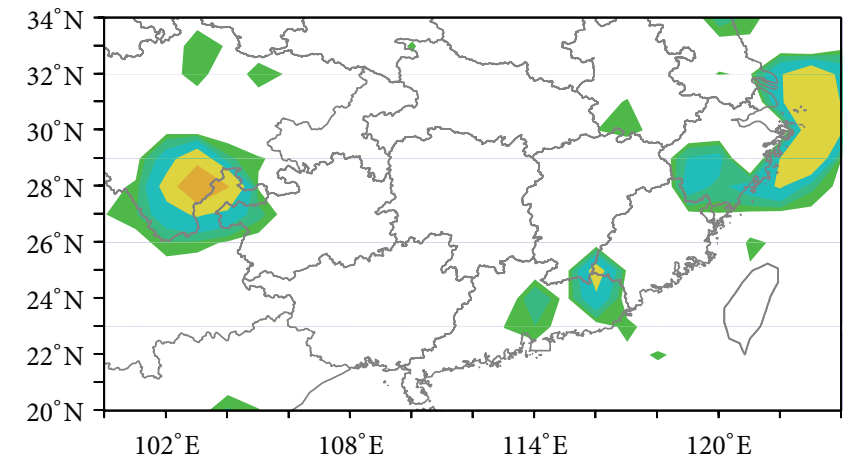

(a) $700 \mathrm{hPa}$

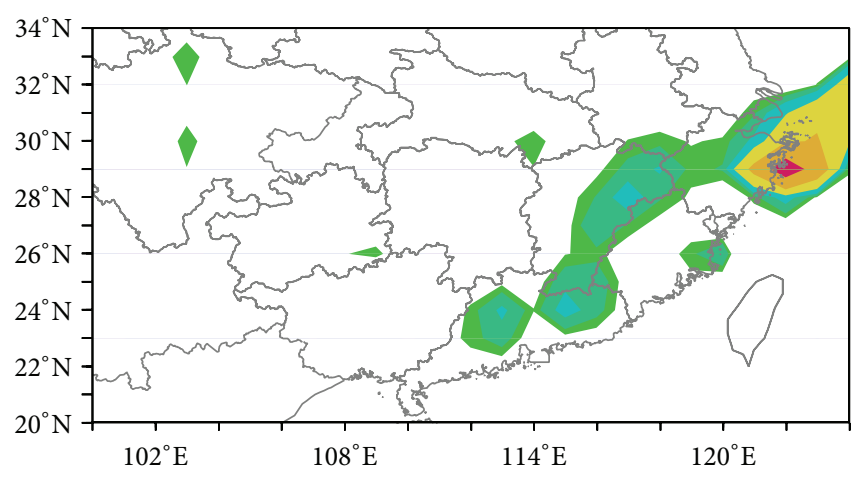

(c) $925 \mathrm{hPa}$

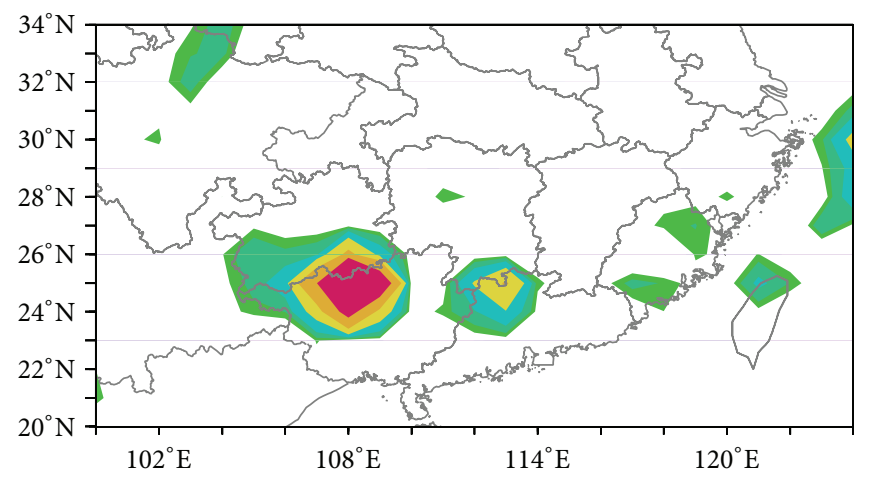

(e) $850 \mathrm{hPa}$
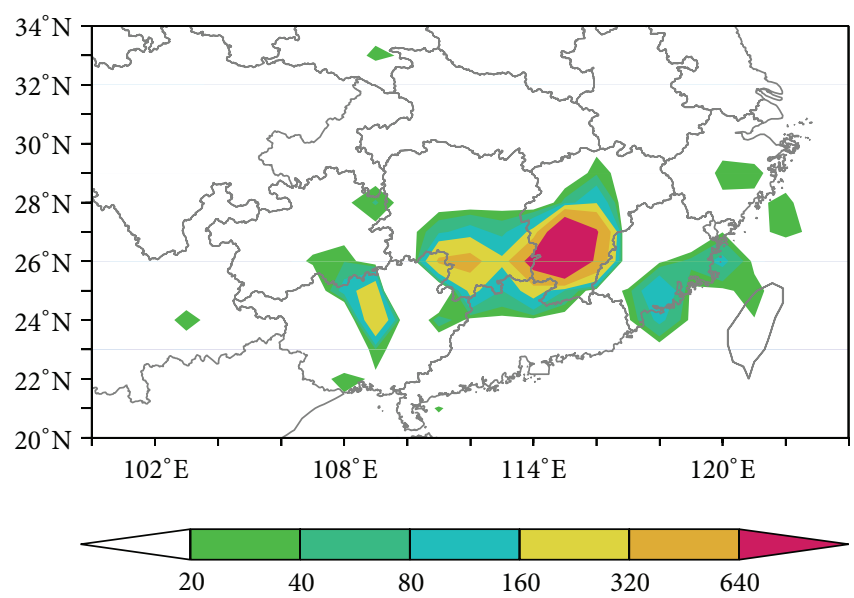

(g) $700 \mathrm{hPa}$

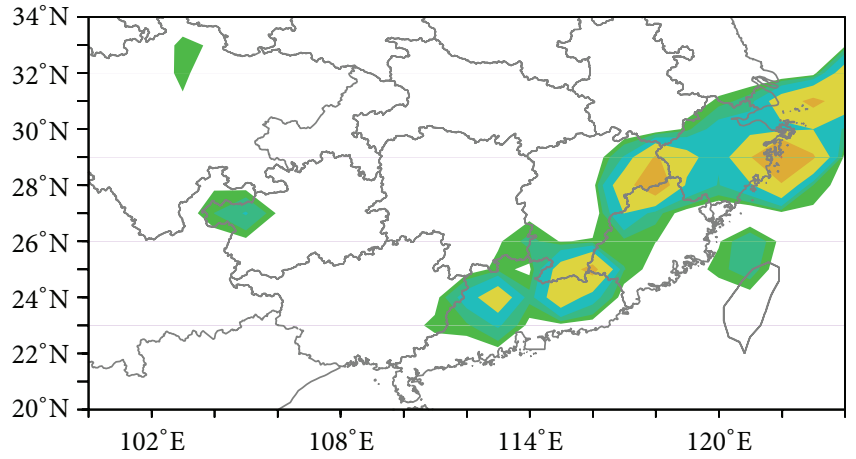

(b) $850 \mathrm{hPa}$

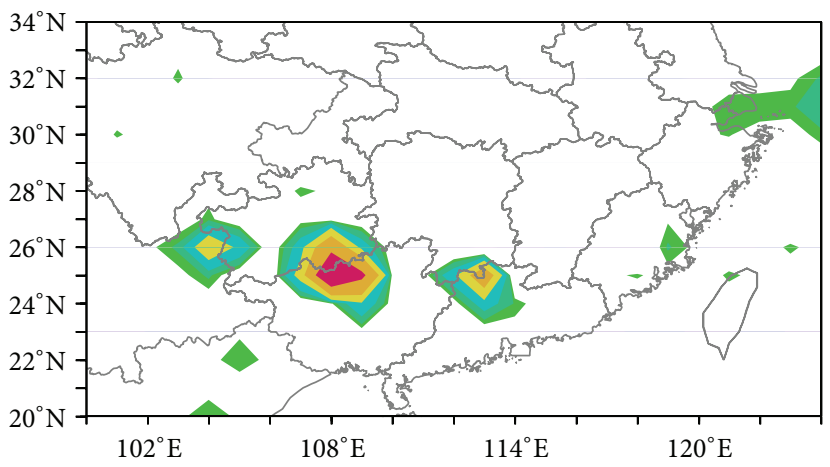

(d) $700 \mathrm{hPa}$

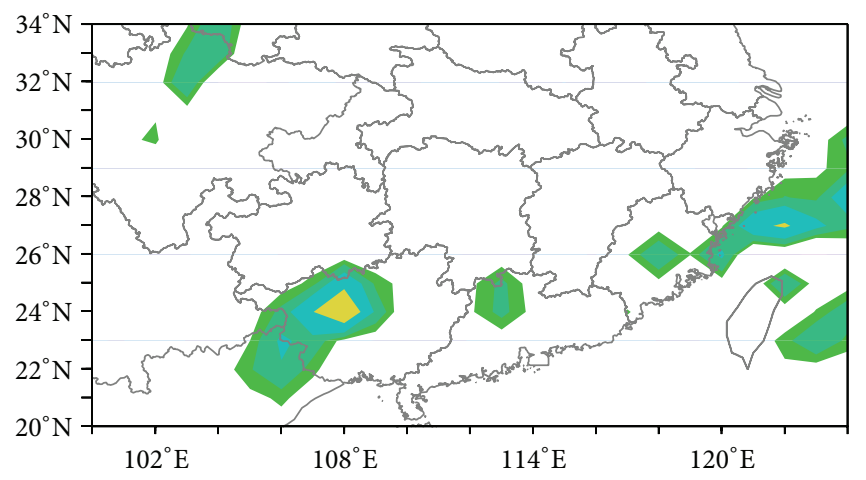

(f) $925 \mathrm{hPa}$

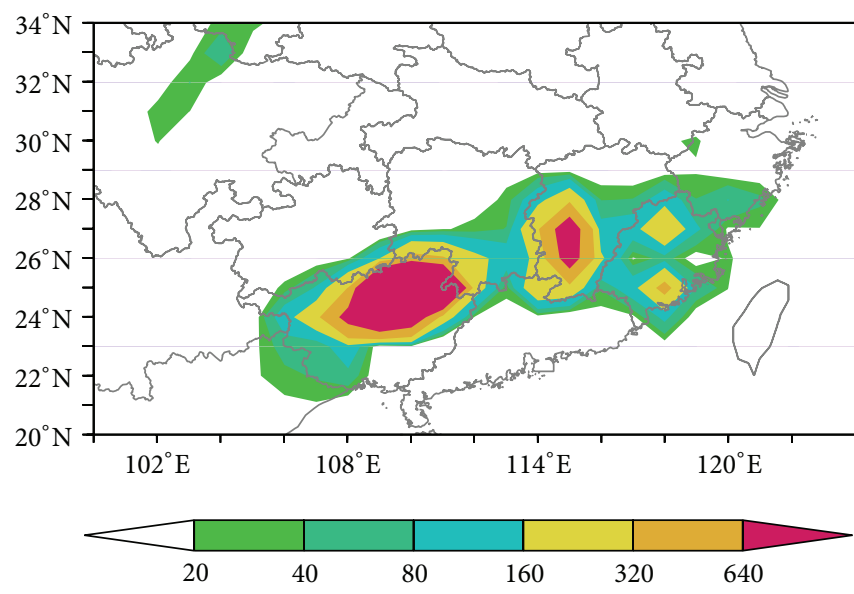

(h) $850 \mathrm{hPa}$

Figure 14: Continued. 


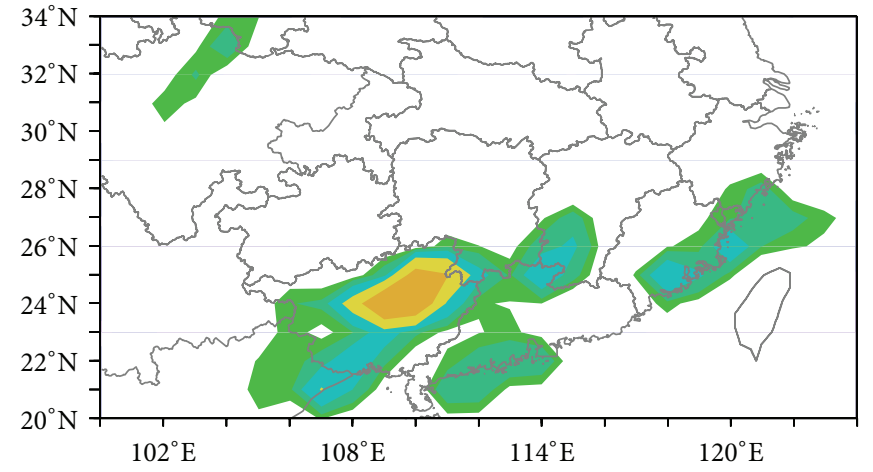

(i) $925 \mathrm{hPa}$

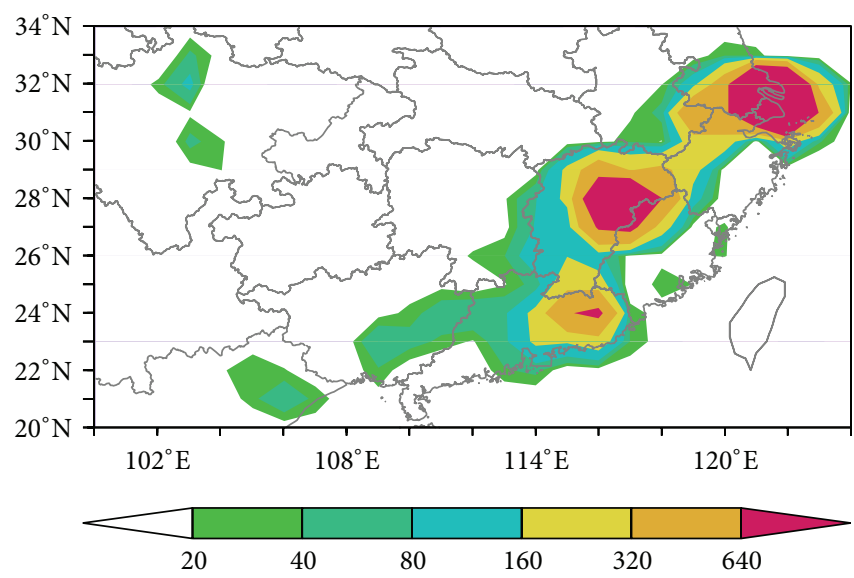

(k) $850 \mathrm{hPa}$

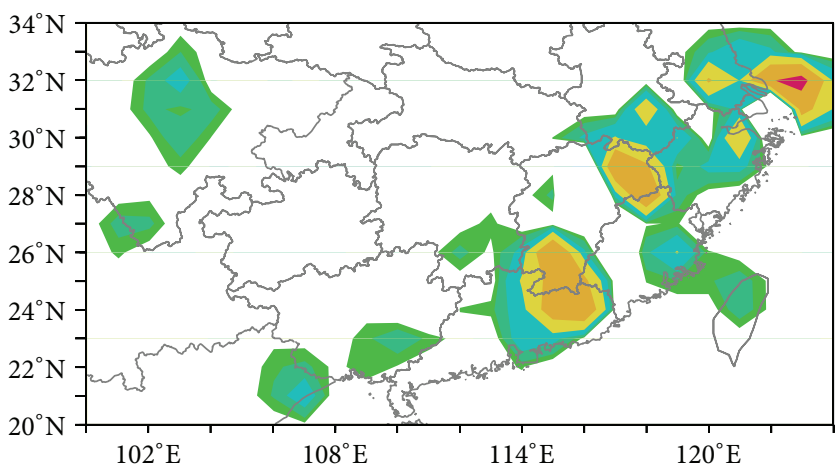

(j) $700 \mathrm{hPa}$

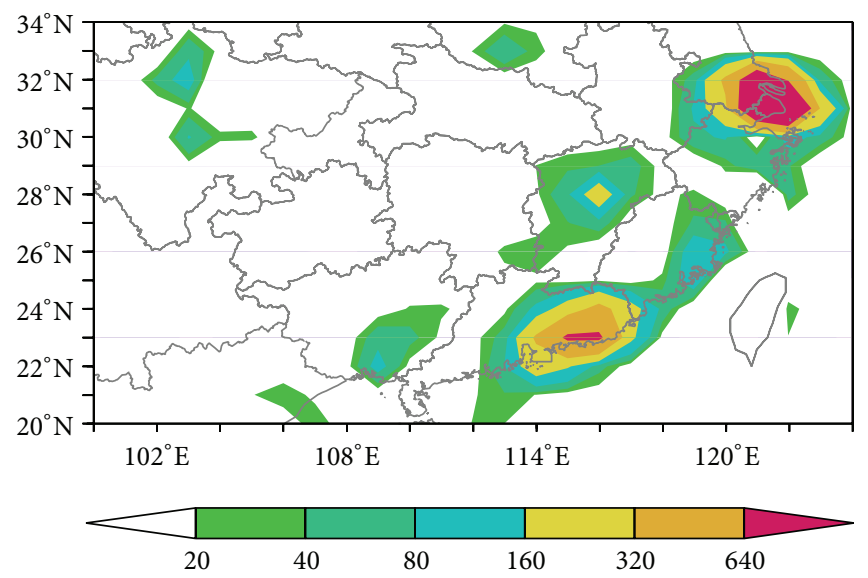

(1) $925 \mathrm{hPa}$

FIGURE 14: Distribution of moist helicity divergence (shaded in $10^{-11} \mathrm{~Pa} / \mathrm{s}^{3}$ ) at $700 \mathrm{hPa}, 850 \mathrm{hPa}$, and $925 \mathrm{hPa}$ averaged over (a), (b), and (c): 12 UTC, June 10-00 UTC, June 11; (d), (e), and (f): 00 UTC, June 11-00 UTC, June 12, (g), (h), and (i): 00 UTC, June 12-00 UTC, June 13; and (j), (k), and (l): 00 UTC, June 13-00 UTC, June 14, 2008.

\section{Acknowledgments}

This work was supported by the National Key Basic Research Development Program Project of China (no. 2012CB417202), the Key Project of the National Natural Science Foundation (no. 91337215), the National Natural Science Foundation of China (nos. 41175093 and 41275051), Forecasters' Special Program of CMA in 2015 (CMAYBY2015-63), Special Fund for Meteorological Research in the Public Interest (GYHY201206042, GYHY201106003, and GYHY201006053), Special Project for Basic Work of Ministry of Science and Technology (2006FY220300), and Key Research and Operation Project of Southwest China Regional Meteorological Center (no. 2010-1).

\section{References}

[1] J. H. Lu, Generality of the Southwest Vortex, China Meteorological Press, Beijing, China, 1986, (Chinese).

[2] Y. H. Kuo, L. S. Chen, and J.-W. Bao, "Numerical simulation of the 1981 Sichuan flood. Part I: evolution of a mesoscale southwest vortex," Monthly Weather Review, vol. 116, no. 12, pp. 2481-2504, 1988.
[3] Z. M. Chen, M. L. Xu, W.-B. Min, and Q. Miu, "Relationship between abnormal activities of south-west vortex and heavy rain the upper reach of Yangtze River during summer of 1998," Plateau Meteorology, vol. 22, no. 2, pp. 162-167, 2003 (Chinese).

[4] S.-M. Fu, J. H. Sun, S. X. Zhao, and W. Li, "The energy budget of a southwest vortex with heavy rainfall over south China," Advances in Atmospheric Sciences, vol. 28, no. 3, pp. 709-724, 2011.

[5] S. Y. Tao, Rainstorms in China, Science Press, Beijing, China, 1980 (Chinese).

[6] Z. S. Wang, Y. H. Wang, and Y. G. Liang, "Numerical experimental study for a heavy rainfall caused by southwest vortex," in Rainstorm Scientific Operational Experiment and Studies on Its Synoptic and Dynamic Theories, pp. 257-267, China Meteorological Press, Beijing, China, 1996.

[7] Z. M. Chen and W. B. Min, "Statistics analysis of southwest vortex," in The Secondary Proceedings of the Qingzang Plateau Meteorology Conference, pp. 368-378, 2000, (Chinese).

[8] Q. Z. Chen, Y. W. Huang, Q. W. Wang, and Z. M. Tan, "The statistical study of the southwest vortex during 1990-2004," Journal of Nanjing University (Natural Sciences), vol. 43, no. 6, pp. 633-642, 2007 (Chinese).

[9] S. T. Gao, "The dynamic action of the disposition of the fluid fields and the topography on the formation of the south-west 
vortex," Chinese Journal of Atmospheric Sciences, vol. 11, no. 3, pp. 263-271, 1987 (Chinese).

[10] G. X. Wu and H. Z. Liu, "Complete form of vertical vorticity tendency equation and slantwise vorticitiy development," Acta Meteorologica Sinica, vol. 57, no. 1, pp. 1-15, 1999 (Chinese).

[11] S. X. Zhao and S. M. Fu, "An analysis on the southwest vortex and its environment fields during heavy rainfall in eastern Sichuan Province and Chongqing in September 2004," Chinese Journal of Atmospheric Sciences, vol. 31, no. 6, pp. 1059-1075, 2007 (Chinese).

[12] H. B. Zhu, S. Deng, and H. Wu, "The development of southwest vortex in conservation of moist potential vorticity," Acta Meteorologica Sinica, vol. 60, no. 3, pp. 343-351, 2002 (Chinese).

[13] G. P. Li, J. Wang, and J. H. Lu, "A potential mechanism of the warm vortex genesisi in Southwest vortex," Quarterly Journal of Applied Meteorology, vol. 2, no. 1, pp. 91-99, 1991 (Chinese).

[14] G. P. Li and X. J. Liu, "The diagnostic analysis of wet potential vorticity of storm rainfall from the southwest vortex in China," Quarterly Journal of Applied Meteorology, vol. 5, no. 3, pp. 354360, 1994 (Chinese).

[15] B. Yu and Y. H. Lin, "A case study of southwest vortex causing heavy rainfall in Eastern Sichuan Basin," Chinese Journal of Atmospheric Sciences, vol. 32, no. 1, pp. 141-144, 2008 (Chinese).

[16] Z. A. Qian, H. D. Gu, and H. Yan, "Numerical simulation of extremely intense rainstorm and Southwest Vortex over Sichuan in July 1981," Acta Meteorologica Sinica, vol. 48, no. 4, pp. 415-423, 1990 (Chinese).

[17] Z. Wang and K. Gao, "Sensitivity experiments of an eastwardmoving southwest vortex to initial perturbations," Advances in Atmospheric Sciences, vol. 20, no. 4, pp. 638-649, 2003.

[18] H. Ma, X. B. Zheng, Y. Hu, T. Y. Zen, and Z. Hong, "Analyses on satellite cloud images and Doppler radar echo features of a MCC rainstorm caused by Southwest vortex," Journal of Nanjing Institute of Meteorology, vol. 33, no. 6, pp. 688-696, 2010 (Chinese).

[19] M. Q. Chen, Q. Y. Gu, Y. B. Wang, and Q. Qing, “The mesoscal convective cloud cluster features of a severe torrential rain caused by southwest vortex," Plateau and Mountain Meteorology Research, vol. 28, no. 4, pp. 66-71, 2008 (Chinese).

[20] R. Davies-Jones, "Streamwise vorticity: the origin of updraft rotation in supercell storms," Journal of the Atmospheric Sciences, vol. 41, no. 20, pp. 2991-3006, 1984.

[21] D. K. Lilly, "The structure and propagation of rotation convective storm. Part 2. Helicity and storm," Journal of the Atmospheric Sciences, vol. 43, no. 2, pp. 126-140, 1986.

[22] G. R. Woodall, "Qualitative forecasting of tornatic activity using storm-relative environmental helicity," in Proceedings of the 16th Conference on Severe Local Storms, American Meteorological Society, pp. 311-315, 1990.

[23] P. M. Markowski, J. M. Straka, E. N. Rasmussen, and D. O. Blanchard, "Variability of storm-relative helicity during VORTEX," Monthly Weather Review, vol. 126, no. 11, pp. 29592971, 1998.

[24] R. Davies-Jones, D. Burgess, and M. Foster, “Test of helicity as a tornado forecast parameter," in Proceedings of the 16th Conference on Severe Local Storms, American Meteorological Society, pp. 588-592, 1990.

[25] Y. H. Li and S. W. Shou, "Rotational wind helicity and its effects on torrential rain processes," Journal of Nanjing Institute of Meteorology, vol. 22, no. 1, pp. 95-102, 1999 (Chinese).
[26] Z. C. Lei, J. Ren, J. X. Ma, and H. Zhou, "A case analysis of Vortex-merging Process in a Jiang-huai River Valley meiyu Rainstorm," Journal of Nanjing Institute of Meteorology, vol. 29, no. 3, pp. 358-363, 2006 (Chinese).

[27] Y. Wang, S. W. Shou, and J. Zhou, "Moisture helicity and its application in diagnostic analysis of a heavy rain in Jiang-Huai basin," Journal of Nanjing Institute of Meteorology, vol. 30, no. 1, pp. 102-106, 2007.

[28] G. X. Wu, Y. P. Cai, and X. Q. Tang, "Moist potential vorticity and slantwise vorticity development," Acta Meteorologica Sinica, vol. 53, no. 4, pp. 389-404, 1995 (Chinese).

[29] G. X. Wu and Y. P. Cai, "Vertical wind shear and downsliding slantwise vorticity development," Chinese Journal of Atmospheric Sciences, vol. 21, no. 3, pp. 273-282, 1997 (Chinese).

[30] P. J. Neiman, F. M. Ralph, G. A. Wick, J. D. Lundquist, and M. D. Dettinger, "Meteorological characteristics and overland precipitation impacts of atmospheric rivers affecting the West coast of North America based on eight years of SSM/I satellite observations," Journal of Hydrometeorology, vol. 9, no. 1, pp. 2247, 2008. 

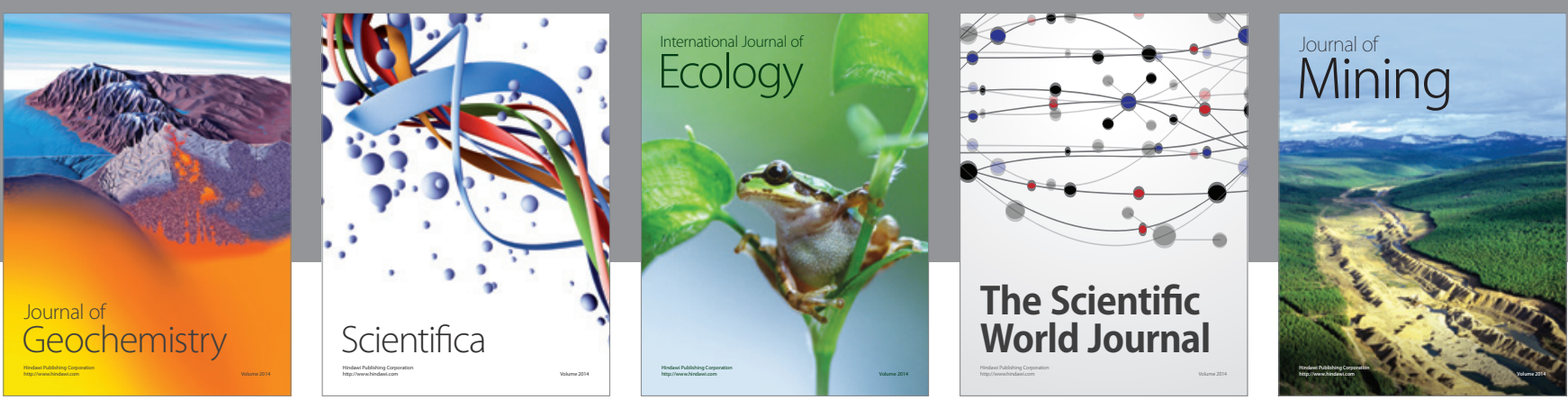

The Scientific World Journal
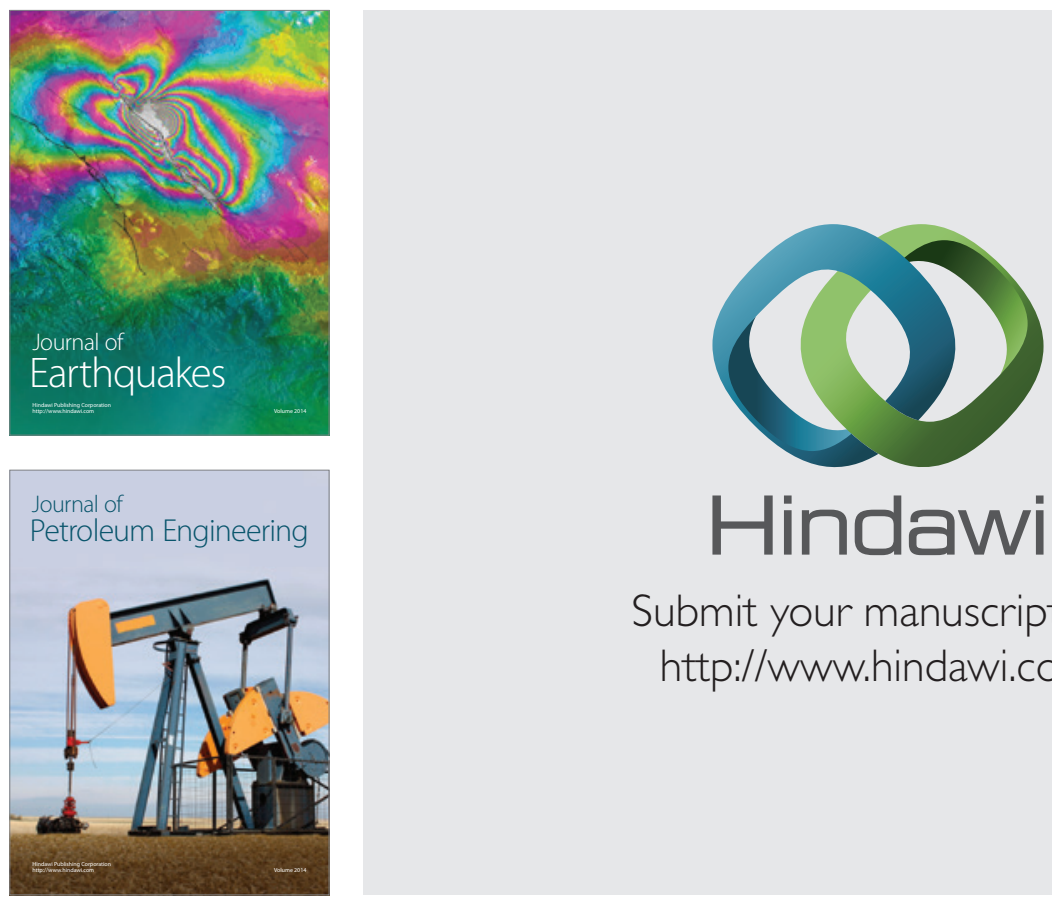

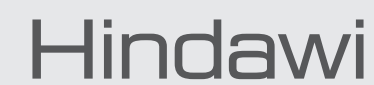

Submit your manuscripts at

http://www.hindawi.com
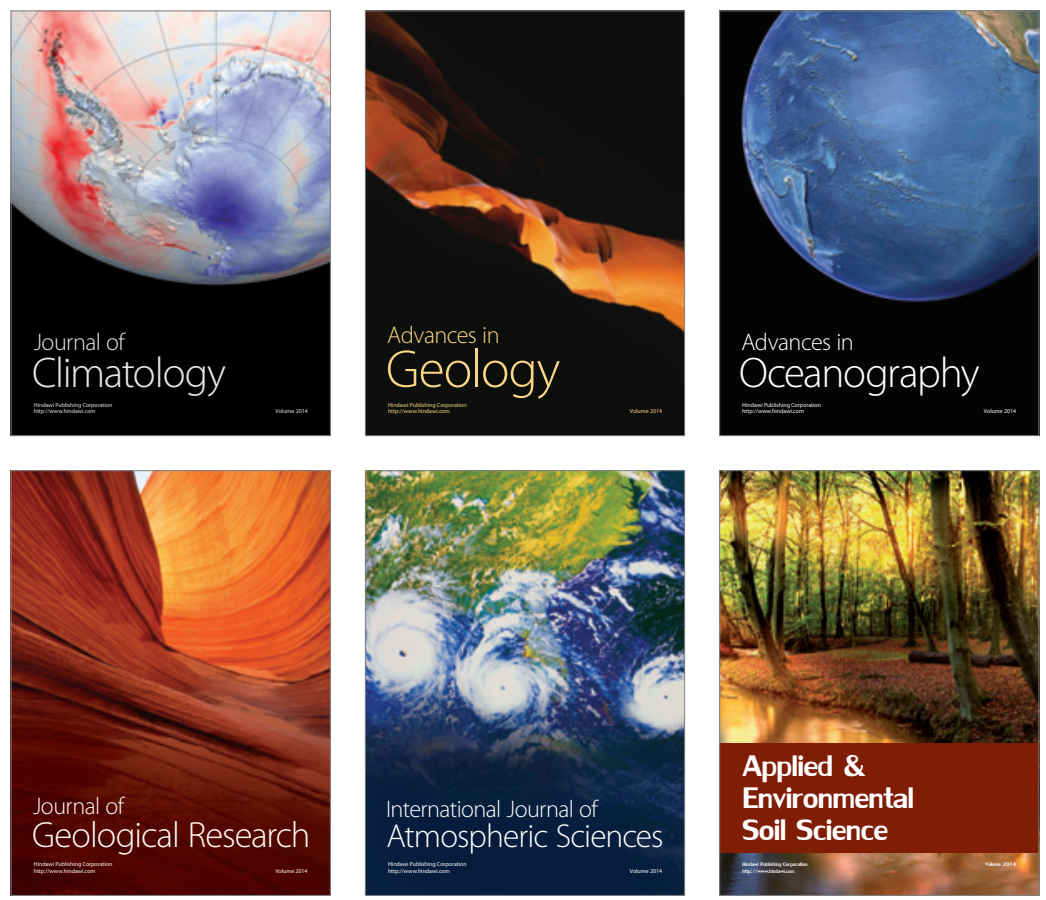
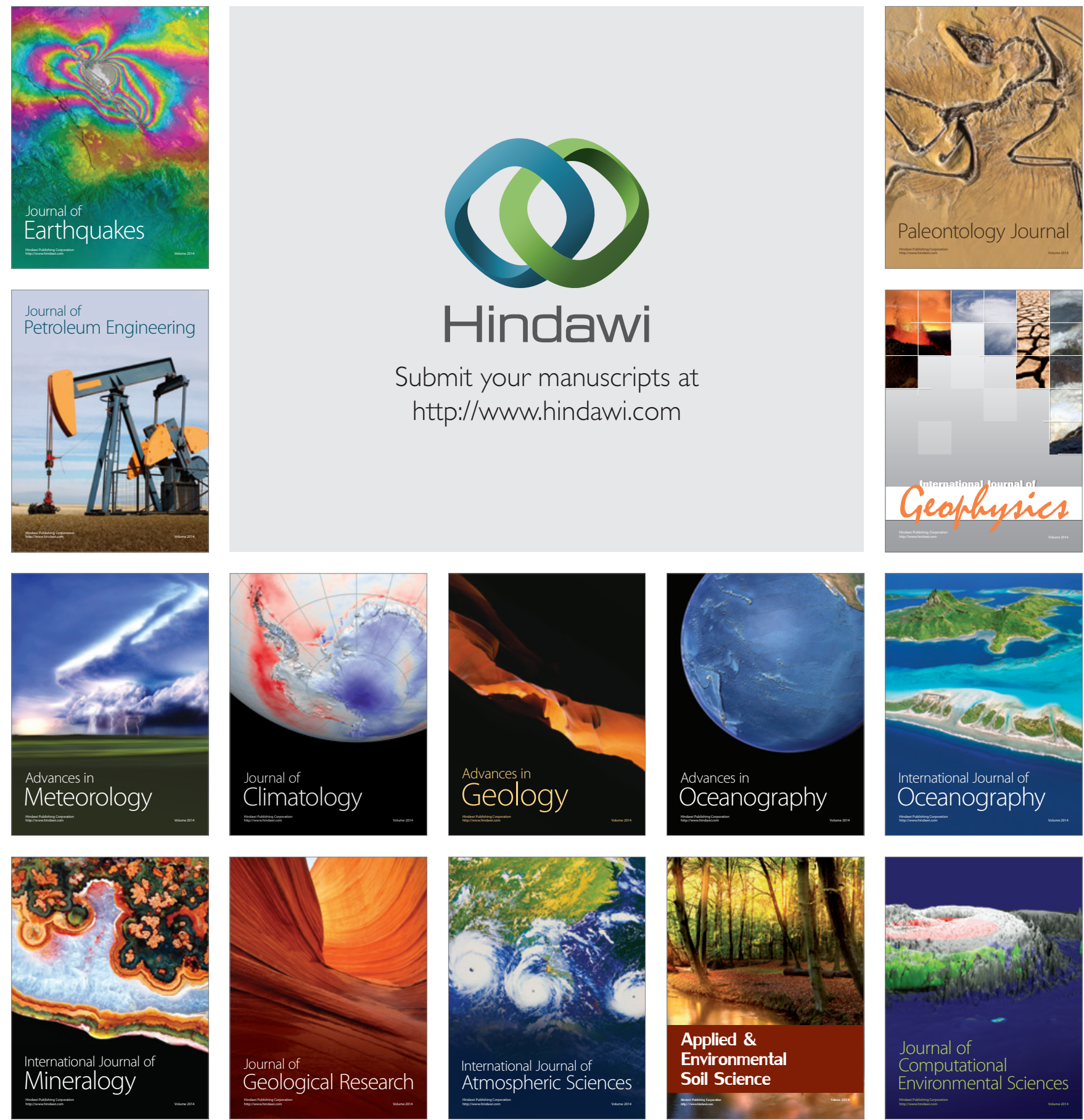